$\underline{\text { Submission to Biomedical Materials }}$

\title{
Electrospinning of Fibrous Polymer Scaffolds Using Positive Voltage or Negative Voltage: A Comparative Study
}

\author{
Ho-Wang Tong, Min Wang * \\ Department of Mechanical Engineering \\ The University of Hong Kong \\ Pokfulam Road, Hong Kong
}

Keywords: electrospinning, poly(hydroxybutyrate-co-hydroxyvalerate), polarity, positive voltage, negative voltage, tissue engineering scaffold

* Correspondence to: Prof. M. Wang at the University of Hong Kong, Hong Kong Fax: +852 $28585415 \quad$ Tel: +85228597903Ｅmail: memwang@hku.hk 


\begin{abstract}
Electrospinning of fibrous tissue engineering scaffolds has been traditionally conducted using positive voltages. In the current study, positive voltage (PV) electrospinning and negative voltage (NV) electrospinning were investigated for forming fibrous membranes of poly(hydroxybutyrate-co-hydroxyvalerate) (PHBV). In both PV-electrospinning and NV-electrospinning, the fiber diameter generally increased with increasing needle inner diameter and PHBV concentration but decreased with increasing working distance. The use of a conductivity-enhancing surfactant, benzyl triethylammonium chloride (BTEAC), significantly reduced PHBV fiber diameters from the micron scale to the sub-micron scale. Interestingly, with increasing applied voltage, the fiber diameter increased for PVelectrospinning but decreased for NV-electrospinning. The PV-electrospun fibrous membranes from solutions without BTEAC (PVEfm) and with BTEAC (PVEfm-B) and NV-electrospun membranes from solutions without BTEAC (NVEfm) and with BTEAC (NVEfm-B) were characterized in terms of their structure, wettability, thermal properties and tensile properties. Both PVEfm and NVEfm exhibited similar water contact angle $\left(\sim 104^{\circ}\right)$ but the contact angle of PVEfm-B or NVEfm-B was not measurable. The elongation at break of PVEfm-B or NVEfm-B was significantly higher than that of PVEfm or NVEfm. Using NV-electrospinning or a combination of NV- and PV-electrospinning may be very useful for developing suitable scaffolds for tissue engineering applications.
\end{abstract}




\section{Introduction}

Electrospinning is a simple and versatile technique for fabricating ultrafine fibers. Since its discovery several decades ago, electrospinning has been investigated for producing fibrous materials for applications in many industries including biomedical engineering [1-2]. To date, a great majority of researchers who performed electrospinning studies applied positive voltages (PVs) to the electrospinning source (i.e. an electrode immersed into the polymer solution or a clip attached to the metallic spinneret) and grounded the fiber collecting device during the fiber formation process, which resulted in the formation of positively charged polymer jets and eventually possibly positively charged fibers. Only a few researchers tried to conduct electrospinning experiments by applying negative voltages (NVs) to the electrospinning source. In 2005, Kalayci et al. noted that "while induction charging using a negative charge is known in electrospinning, experimental studies are limited" [3]. In a review article published in 2007, Greiner and Wendorff pointed out that "electrostatic charging of the fibers plays a major role in tissue formation during the deposition on the substrate, but this issue has only been discussed in a few papers" [4]. In spite of the awareness of limited studies on NV-electrospinning, NV-electrospinning still has not received much attention from researchers. The limited studies on NV-electrospinning are summarized in table $1[3,5-9]$. From this table, it is obvious that: (1) the few researchers mainly focused on exploratory studies without realizing the potential biomedical implications of NV-electrospinning, and (2) there has been virtually no report on NV-electrospinning of tissue engineering scaffolds. However, in the tissue engineering field, NV-electrospinning may have significant implications such as improvement of fiber alignment, influences of surfactant, fiber influence on cell behaviour, etc.

Electrospun aligned fibers are suitable candidates for constructing scaffolds for regenerating different types of body tissues such as ligaments [10], nerves [11], skeletal muscles [12], and vascular tissues [13]. When a high speed rotating disc was used to collect aligned fibers during electrospinning, residual positive charges on electrospun fibers repelled the incoming fibers, thus affecting the degree of fiber alignment [14]. Similarly, when a high speed rotating cylinder was used to obtain multilayered structures consisting of aligned fibers, fiber alignment at the bottom layer was reliable while fiber alignment at the 
upper layer worsened, which was believed to be caused by charge repulsion (Tong HW and Wang M, unpublished). The use of PV- and NV-electrospinning simultaneously to form aligned fibers may solve the fiber alignment problem because the residual negative charges on the NV-electrospun fibers would not repel the incoming PV-electrospun fibers.

Surfactants are commonly used for electrospinning fibers in order to suit one or more of the following four purposes: (1) to improve the electrospinnability, (2) to reduce the electrospun fiber diameter significantly, (3) to eliminate the formation of beaded fibers, and (4) to form core-shell fibers by emulsion electrospinning. Due to different applications, the surfactants used for electrospinning can be cationic [15], anionic [16] or non-ionic [17]. These surfactants, which may carry positive or negative charges, could have different behaviours when NV-electrospinning is employed instead of the conventional PVelectrospinning. The use of surfactant for NV-electrospinning may have significant importance in the tissue engineering field due to its influence on the characteristics of scaffolds formed, which arise from the distinctive process of fiber formation in an electric field under high NV.

It is well known in the biomaterials field that the polarity and density of electrical charges on biomaterials surface play an important role in affecting the behaviour of cells seeded on the biomaterial [18-19]. It was also found that charges could be retained on PV-electrospun fibers for relatively long times [7, 20-21]. While fibrous scaffolds formed through electrospinning can bear charges and these charges may be retained on scaffolds for some time, the PV- and NV-electrospun fibrous scaffolds may have significant effects on cell reaction and tissue formation.

Poly(hydroxybutyrate-co-hydroxyvalerate) (PHBV), a natural, biocompatible and biodegradable polymer, is a good candidate material for tissue engineering applications. Many researchers have already demonstrated the suitability of using PHBV or PHBV-based materials for biomedical applications. Xin et al. fabricated PHBV microspheres covalently conjugated with different proteins and showed their potential for liver tissue engineering [22]. The use of PHBV for cartilage regeneration was reported by Liu et al., who found that PHBV foams seeded with pre-differentiated human adipose-derived stem cells were capable of producing neo-cartilage in a heterotopic animal model [23]. Using PV-electrospinning, 
PHBV has been successfully fabricated into ultrafine fibers having different diameters, morphologies and compositions in our previous studies [24-26]. It is of both scientific and technological importance that NV-electrospinning of PHBV fibers is investigated. The present study therefore employed both NVelectrospinning and PV-electrospinning in forming PHBV fibrous membranes and compared properties of NV-electrospun PHBV fibrous membranes with those of PV-electrospun PHBV fibrous membranes. The results obtained in this study will help develop novel tissue engineering scaffolds employing NVelectrospinning.

\section{Materials and methods}

\subsection{Materials}

PHBV with a molecular weight of 310,000 and containing 2.9 mol\% of 3-hydroxyvalerate was obtained from Tianan Biologic Material Ltd., China. The solvent, chloroform (VWR BDH Prolabo, UK), for making PHBV polymer solution was of analytical grade. The polymer and solvent were used in the asreceived state without further purification. The electrical conductivity-enhancing surfactant, benzyl triethylammonium chloride (BTEAC), was obtained from Fluka, Germany.

\subsection{Solution preparation and electrospinning}

To prepare PHBV solutions for electrospinning, PHBV was dissolved in chloroform with heating $\left(50^{\circ} \mathrm{C}\right)$ and stirring (1000 rpm) for about 30 minutes using a hotplate magnetic stirrer (RET control visc IKAMAG ${ }^{\circledR}$, USA). For some PHBV solutions, to enhance their electroconductivity for electrospining and therefore obtain smaller diameter fibers, small amounts of BTEAC ( 0 to $2 \mathrm{wt} \%$, with respect to the mass of PHBV) were dissolved in the PHBV solutions. A traditional electrospinning setup was employed for PV-electrospinning [26]. The experimental setup for NV-electrospinning was the same as the PVelectrospinning setup except that the high positive voltage power supply was replaced by the high negative voltage power supply (Gamma High Voltage Research, USA). Because of this change, the 
direction of the electric field was reversed. Charge rearrangement still occurred but all positions for attracting positive charges originally became positions for attracting negative charges, and vice versa. As a result, a polymer jet, which may carry negative charges, was initiated. Apart from PHBV fibers, PHBV films were made and the wettability and thermal properties of the PHBV films were compared with that of the PHBV fibers. The PHBV films were prepared by the solvent-casting method. Briefly, $3 \mathrm{~mL}$ of PHBV solution with a concentration of $15 \% \mathrm{w} / \mathrm{v}$ was transferred to a Petri dish and the dish was gently shaken in order to obtain a homogeneous layer of PHBV solution on the dish. After evaporation of chloroform, a flat solvent-cast film was obtained.

\subsection{Diameter of the electrospun fibers}

To investigate the influence of different electrospinning parameters on fiber diameter, using PV or NV, the PHBV fibers were electrospun with different polymer solution concentrations (from 5 to $25 \% \mathrm{w} / \mathrm{v}$ ), solution feeding rates (from 1 to $9 \mathrm{ml} / \mathrm{h}$ ), needle inner diameters (from 0.4 to $1.2 \mathrm{~mm}$ ), working distances (from 5 to $30 \mathrm{~cm}$ ), applied voltages (from 5 to $35 \mathrm{kV}$ for PV-electrospinning; from -5 to $-35 \mathrm{kV}$ for $\mathrm{NV}$ electrospinning), and BTEAC contents (from 0 to $2 \mathrm{wt} \%$, with respect to the mass of PHBV). The diameter of the PV- and NV-electrospun PHBV fibers were then investigated systematically using a scanning electron microscope (SEM, Stereoscan 440, UK). For determining the diameters and diameter distributions of fibers electrospun under different conditions, each SEM micrograph was analysed using an image analysis program (UTHSCSA Image Tool). For each type of fibers, the fiber diameter was measured at 100 different points.

\subsection{Fibrous membranes for comparative study}

For the comparative study, four groups of PHBV fibrous membranes were made: (1) PV-electrospun fibrous membranes from PHBV solutions without BTEAC (designated as "PVEfm"), (2) PV-electrospun fibrous membranes from PHBV solutions with BTEAC (designated as "PVEfm-B"), (3) NV-electrospun fibrous membranes from PHBV solutions without BTEAC (designated as "NVEfm"), (4) NV-electrospun 
fibrous membranes from PHBV solutions with BTEAC (designated as "NVEfm-B"). To fabricate these four groups of membranes, the PHBV solution concentration was fixed at $15 \% \mathrm{w} / \mathrm{v}$ while the electrospinning processing parameters were kept constant as follows: (a) working distance $=15 \mathrm{~cm}$, (b) solution feeding rate $=1 \mathrm{ml} / \mathrm{h},(\mathrm{c})$ needle inner diameter $=0.5 \mathrm{~mm}$, and (d) applied voltage $= \pm 15 \mathrm{kV}$. The BTEAC content was $2 \mathrm{wt} \%$ for the formation of PVEfm-B and NVEfm-B. Each of these four groups of fibrous membranes was subjected to structural analysis by Fourier transform infrared (FTIR) spectroscopy, wettability evaluation by water contact angle measurement, thermal analysis by differential scanning calorimetry (DSC), and tensile testing.

\subsubsection{Structure}

FTIR spectroscopic analysis of the fibrous membranes was conducted using an FTIR equipment (Spectrum BX FTIR spectrometer from Perkin-Elmer, USA) over a range of $1000-2000 \mathrm{~cm}^{-1}$ at a resolution of $2 \mathrm{~cm}^{-1}$.

\subsubsection{Wettability}

The wettability of fibrous membranes was studied using a contact angle measuring machine (SL200B, Shanghai Solon Tech Inc Ltd, China). The contact angles of PHBV solvent-cast films were also determined. Each specimen was first attached onto the holder of the contact angle measuring machine. A drop of distilled water $(0.4 \mu \mathrm{L})$ was then dropped onto the specimen surface. The contact angle of the water drop on the specimen surface was determined at room temperature following a standardized procedure and using a proprietary software. Three measurements were taken at different locations of the same specimen and the average value was obtained. The contact angle was expressed as the mean \pm standard deviation.

\subsubsection{Thermal properties}


DSC thermograms were obtained using a differential scanning calorimeter (Pyris 6 DSC from PerkinElmer, USA). Specimens of the four groups of fibrous membranes and PHBV solvent-cast films were sealed in aluminium pans and weights of approximately $3 \mathrm{mg}$ were used. An empty pan was used as reference. All experiments were conducted at a heating rate of $10^{\circ} \mathrm{C} / \mathrm{min}$ from 4 to $200^{\circ} \mathrm{C}$. Melting temperatures were determined from the thermograms. The enthalpy of fusion, $\Delta \mathrm{H}_{\mathrm{f}}$, was also measured by DSC. While the heat of fusion value for $100 \%$ crystalline PHBV, $\Delta \mathrm{H}_{0, \mathrm{PHBV}}$, was $146 \mathrm{~J} / \mathrm{g}$ [27], the apparent degree of crystallinity, $\mathrm{X}_{\mathrm{c}}$, of PHBV fibers or films was calculated using the following equation:

$$
X_{c}=\frac{\Delta H_{f}}{\Delta H_{0, P H B V}}
$$

\subsubsection{Tensile properties}

Mechanical evaluation of fibrous membranes was performed by conducting tensile tests. The thickness of each fibrous membrane was measured using a digital micrometer (Mitutoyo, Japan). The tensile testing was performed using a tabletop Instron tester (Model 5848, Instron Inc., USA) with a load cell of 10 N. A cross-head speed of $2 \mathrm{~mm} / \mathrm{min}$ was used for all tensile tests. All fibrous membranes were cut into rectangular strips $(5 \times 30 \mathrm{~mm})$ and the strips were tested to the point of tensile failure. The machinerecorded data was used to construct tensile stress-strain curves of the specimens. The ultimate tensile strength $\left(\sigma_{\mathrm{UTS}}\right)$, Young's modulus $(E)$ and elongation at break $(\varepsilon)$ were determined from three independent strips obtained from each of the four above-mentioned groups of electrospun fibrous membranes. The values of these properties were expressed as the mean \pm standard deviation.

\subsubsection{Statistical analysis}

All quantitative data were expressed as mean \pm standard deviation. Statistical analyses were performed using Student's $t$ test. A value of $p<0.05$ was considered to be statistically significant and $p<0.01$ highly significant. 


\section{Results and discussion}

In normal description, when the voltage changes from a less negative value $(e . g .-15 \mathrm{kV})$ to a more negative value (e.g. $-20 \mathrm{kV}$ ), the word "decrease" is used to describe the change. However, in the current study, the electric field strength for the applied voltage rather than the numerical value (e.g. $-15 \mathrm{kV})$ was considered. Therefore, in this article, when the applied voltage changes from $-15 \mathrm{kV}$ to $-20 \mathrm{kV}$, it is stated that the voltage "increases" from $-15 \mathrm{kV}$ to $-20 \mathrm{kV}$.

\subsection{Effect of needle inner diameter}

To study the effect of needle inner diameter on PV-electrospun PHBV fibers, electrospinning parameters except the needle inner diameter were fixed as follow: (1) applied voltage $=15 \mathrm{kV}$, (2) solution feeding rate $=5 \mathrm{ml} / \mathrm{h}$, (3) working distance $=15 \mathrm{~cm}$, (4) concentration of PHBV solution $=8 \% \mathrm{w} / \mathrm{v}$. The effect of needle inner diameter on NV-electrospun PHBV fibers was studied similarly except that the applied voltage was $-15 \mathrm{kV}$. Figure $1(A-B)$ and figure $1(C-D)$ display SEM micrographs of PV- and NVelectrospun PHBV fibers obtained using different needle diameters, respectively. No matter PV or NV was used, ultrafine PHBV fibers without beads could only be electrospun from a needle with inner diameter of $0.7 \mathrm{~mm}$ or below, provided that the polymer solution concentration was optimized while the polymer with suitable molecular weight was used. When the needle inner diameter was above $0.7 \mathrm{~mm}$, clogging occurred at the needle tip in a very short period time before sufficient fibers could be collected. The average diameter of the electrospun PHBV fibers generally increased with increasing needle inner diameter, as shown in figure $1(E)$. This result is the same as those obtained by a few research groups on PV-electrospinning of different polymers [28]. Larger needle diameter would result in the formation of larger Taylor cone at the start of electrospinning, which facilitated larger initial polymer jet and hence a larger resulting fiber. It can also been seen in figure $1(E)$ that when the inner diameter of the needle was small (e.g. $0.4 \mathrm{~mm}$ ), PV-electrospinning was preferred for the formation of small-diameter PHBV fibers. However, when the inner diameter of the needle was large $($ e.g. $0.7 \mathrm{~mm})$, it was better to employ NVelectrospinning for forming small-diameter PHBV fibers. This result demonstrated that the PHBV fibers 
obtained from the two different techniques (i.e. PV-electrospinning and NV-electrospinning) may exhibit different fiber diameters without changing the needle inner diameter and other processing parameters, even though the effect of technique variation on fiber diameter is not as significant as that of the needle inner diameter. No matter $\mathrm{PV}$ or $\mathrm{NV}$ is used, a needle with diameter of $0.8 \mathrm{~mm}$ or larger is not recommended for the electrospinning of PHBV because the large needle causes significant exposure of the solution to the air during electrospinning. As a result, clogging at the tip of the needle can occur easily and only an insufficient amount of fibers can be electrospun before the needle is blocked by solidified polymer.

\subsection{Effect of solution feeding rate}

To study the effect of solution feeding rate, electrospinning took place at a voltage of $15 \mathrm{kV}$ (or $-15 \mathrm{kV}$ for NV-electrospinning), a needle inner diameter of $0.4 \mathrm{~mm}$ and a working distance of $15 \mathrm{~cm}$ by using 8 $\% \mathrm{w} / \mathrm{v}$ PHBV solution. The only parameter that was changed was the solution feeding rate. In both situations (i.e. PV- and NV-electrospinning), the fiber morphologies were similar when the solution feeding rate was varied between 1 and $7 \mathrm{ml} / \mathrm{h}$, as shown in figure $2(A-B)$ and figure $2(C-D)$. The relationship between solution feeding rate and the average diameter of the PHBV fibers was plotted and is shown in figure 2(E). The diameters of the beaded fibers in SEM micrographs were not considered in constructing this plot. As could be seen from figure 2(E), the diameter of the fibers electrospun from the 8 $\% w / v$ PHBV solution did not change significantly with the solution feeding rate even though one can argue that the PHBV fiber diameter slightly increased with increasing solution feeding rate during NVelectrospinning. The average diameter of the electrospun PHBV fibers was about $1.4 \mu \mathrm{m}$ as the solution feeding rate was varied from 1 to $7 \mathrm{ml} / \mathrm{h}$. Although Tan et al. [29] and Cui et al. [30] did not investigate the solution feeding rate effect for NV-electrospinning, they also observed that the fiber diameter was not significantly affected by varying the solution feeding rate for PV-electrospinning. These results indicate that the cross-section of the initiating jet was not affected by the solution feeding rate significantly. However, beaded fibers were formed when the solution feeding rate was increased to $9 \mathrm{ml} / \mathrm{h}$. 


\subsection{Effect of applied voltage}

To study the effects of applied voltage, parameters except applied voltage were fixed as follows: (1) working distance $=20 \mathrm{~cm}$, (2) solution feeding rate $=5 \mathrm{ml} / \mathrm{h}$, (3) needle inner diameter $=0.8 \mathrm{~mm}$, (4) PHBV solution concentration $=8 \% \mathrm{w} / \mathrm{v}$. The morphologies of the PV- and NV-electrospun PHBV fibers at different applied voltages are shown in figure $3(A-B)$ and figure $3(C-D)$, respectively. When a PVelectrospinning setup was used, higher voltage facilitated the formation of larger PHBV fibers [figure $3(E)]$. However, the fiber diameter slightly decreased with increasing voltage when NV-electrospinning was employed [figure 3(E)]. This could be explained by the presence of negatively charged groups in the electrospun polymer jet consisting of both polymer (i.e. PHBV) molecules and solvent (i.e. chloroform) molecules. The negatively charged groups could partly neutralize the positively charged polymer jet during PV-electrospinning but superimpose on the negatively charged polymer jet during NVelectrospinning, resulting in lower amount of charges on positively charged jet but higher amount of charges on negatively charged jet, even though the absolute values of the applied PV and NV were the same. Therefore, the increase of the NV caused increase of the electrostatic stress on the jet, and the increased stress stretched the jet into thinner fibers effectively. It appears that the voltage effect on fiber diameter could be different, depending on the polarity of the solution and the electrical properties of the polymer. This may also provide an explanation for the seemingly contradictory results reported by different electrospinning groups as some of the researchers found that the fiber diameter increased with voltage [20, 31-33] while other found that the fiber diameter decreased with increasing voltage [28, 3438], although the effect of voltage was not as strong as that of the polymer solution concentration. Electrospinning of polymer fibers requires the formation of a jet of solution from the pendent droplet suspended at the needle tip, but no jet could be ejected when the applied electrospinning voltage was insufficient $(<|-5| \mathrm{kV})$. At about $\pm 10 \mathrm{kV}$, the fibers were usually electrospun intermittently, accompanied by some polymer solution droplets. The droplets falling on the collector would become polymer blocks, which certainly damaged the fibrous structure consisting of ultrafine fibers. At very high voltages $(>|-25|$ 
$\mathrm{kV}$ ), the trajectory of the polymer solution jet became very unstable. The jet was easily attracted by nearby objects such as the syringe pump and some electrical wires. Therefore, it was difficult to produce a large mesh of fibers on the fiber collector using such high applied voltages.

\subsection{Effect of working distance}

To investigate the effect of working distance, these electrospinning parameters were fixed: (1) applied voltage $=15 \mathrm{kV}$ (or $-15 \mathrm{kV}$ for NV-electrospinning), (2) solution feeding rate $=5 \mathrm{ml} / \mathrm{h},(3)$ needle inner diameter $=0.8 \mathrm{~mm}$, (4) PHBV solution concentration $=8 \% \mathrm{w} / \mathrm{v}$. Figure $4(A-B)$ and figure $4(C-D)$ show the PV- and NV-electrospun PHBV fibers at different working distances, respectively. The relationship between the working distance and the average fiber diameter is shown in figure $4(E)$. As the working distance was increased from $15 \mathrm{~cm}$ to $25 \mathrm{~cm}$, the average fiber diameter was reduced without formation of beaded fibers or polymer blocks, no matter PV- or NV-electrospinning was employed. Yördem et al. also found that the fiber diameter decreased with increasing working distance, though they only performed the PV-electrospinning [39]. It can also been seen in figure 4(E) that when large-diameter PHBV fibers were required, it was better to employ PV-electrospinning in addition to decreasing the working distance. However, when small-diameter PHBV fibers were required, NV-electrospinning was preferred in addition to increasing the working distance. This result demonstrated the difference between the PHBV fibers obtained from the two different techniques (i.e. PV-electrospinning and NV-electrospinning), even though the working distance was still the dominant factor that influenced the fiber diameter. Further increase in working distance to $30 \mathrm{~cm}$ or above resulted in the formation of beaded fibers and / or polymer blocks because longer working distances allowed longer time for the jet to contract, thus giving more opportunity for the remaining solution to form beads. If the working distance was further increased dramatically ( $>>$ $30 \mathrm{~cm}$ ), the electrostatic field strength became very low and hence no fibers could be formed.

\subsection{Effect of polymer solution concentration}


To assess the effect of polymer solution concentration, electrospinning took place at a solution feeding rate of $1 \mathrm{ml} / \mathrm{h}$, an applied voltage of $15 \mathrm{kV}$ (or $-15 \mathrm{kV}$ for $\mathrm{NV}$-electrospinning), a needle inner diameter of $0.4 \mathrm{~mm}$ and a working distance of $15 \mathrm{~cm}$. The only parameter that was changed was the PHBV solution concentration. No matter PV- or NV-electrospinning was employed, beaded fibers were formed at the PHBV solution concentration of $5 \% \mathrm{w} / \mathrm{v}$ or below because low polymer solution concentration often caused incomplete evaporation of solvent during the fiber formation process. As a result, it was difficult to stretch the "wet" fiber by the electric force and contraction of extra solution along the "wet" fiber occurred easily. The extra solution became the beads eventually. In contrast, when the solution concentration was above $25 \% \mathrm{w} / \mathrm{v}$, due to rapid solidification of the pendent droplet suspended at the needle tip, clogging easily occurred at the tip of the electrospinning needle, no matter the solution was electrospun using a PV or NV. Ultrafine fibers without beads could be fabricated by electrospinning when the solution concentration was within the medium range $(8 \% \mathrm{w} / \mathrm{v}$ to $25 \% \mathrm{w} / \mathrm{v})$ [figures $5(A-D)$ ]. Within this range of solution concentration, the average fiber diameter generally increased with increasing polymer solution concentration [figure $5(E)$ ] because the solvent would finally be evaporated from the jet and the jet would become a fiber eventually. It is worth noting that the selection of an appropriate electrospinning technique (i.e. PV-electrospinning or NV-electrospinning) may help reduce the PHBV fiber diameter. When small-diameter PHBV fibers are required, NV-electrospinning is preferred because the average diameter of the NV-electrospun PHBV fibers was generally lower than that of the PVelectrospun PHBV fibers, even though the polymer solution concentration and other processing parameters were kept constant. This result is especially valid at a low PHBV solution concentration (e.g. $15 \% \mathrm{w} / \mathrm{v})$, as shown in figure $5(E)$.

\subsection{Effect of the concentration of conductivity-enhancing surfactant}

The following parameters were fixed in the experiments: (1) applied voltage $=15 \mathrm{kV}$ (or $-15 \mathrm{kV}$ for NVelectrospinning), (2) solution feeding rate $=1 \mathrm{ml} / \mathrm{h}$, (3) needle inner diameter $=0.5 \mathrm{~mm}$, (4) working distance $=15 \mathrm{~cm}$, and (5) PHBV solution concentration $=15 \% \mathrm{w} / \mathrm{v}$. The effect of the concentration of 
conductivity-enhancing surfactant (i.e. BTEAC) on fiber diameter was investigated by changing the BTEAC concentration from 0 to $2 \mathrm{wt} \%$. Figure $6(A-B)$ and figure $6(C-D)$ show the PV- and NVelectrospun PHBV fibers at different BTEAC concentrations, respectively. The relationship between the concentration of BTEAC and the average fiber diameter is shown in figure $6(E)$. Without BTEAC, PHBV fibers normally exhibited diameters above $2 \mu \mathrm{m}$, no matter PV- or NV-electrospinning was employed. When a small amount of BTEAC (1 wt \%) was dissolved in the PHBV solution for electrospinning, the average fiber diameter decreased drastically to a few hundred nanometers in both PV- and NVelectrospinning. Further decrease in average fiber diameter was observed when the BTEAC concentration became $2 \mathrm{wt} \%$. However, PHBV solutions having more than $2 \mathrm{wt} \%$ of BTEAC could not be used for either PV- or NV-electrospinning because the jet became very unstable, resulting in no fiber formation. These results implied that the electric force tended to stretch the jet into thinner fiber when the conductivity of the polymer solution, and hence the polymer jet, increased. When BTEAC was dissolved in the PHBV solution for electrospinning, the diameters of the NV-electrospun fibers were generally finer than that of the PV-electrospun fibers. BTEAC is an anionic surfactant that may superimpose the negative charges on the polymer jet during NV-electrospinning but partly neutralize the positive charges during PV-electrospinning. Therefore, the electric force under respective voltages should stretch the polymer jet into finer fibers during NV-electrospinning more easily than PV-electrospinning.

\section{7. $\quad$ Structures of the $P V$ - and NV-electrospun fibrous membranes}

The FTIR spectra of the four groups of fibrous membranes (i.e. PVEfm, PVEfm-B, NVEfm, and NVEfmB) are shown in figure 7. The spectra of these fibrous membranes exhibited several common peaks due to the matrix polymer PHBV. These absorption peaks were the stretching vibration of $\mathrm{C}=\mathrm{O}$ at $1728 \mathrm{~cm}^{-1}$ (Peak 1), the asymmetrical bending of $\mathrm{CH}_{3}$ at $1462 \mathrm{~cm}^{-1}$ (Peak 2), the $\mathrm{CH}_{2}$ bending at $1454 \mathrm{~cm}^{-1}$ (Peak 3), the symmetrical bending vibration of $\mathrm{CH}_{3}$ at $1382 \mathrm{~cm}^{-1}$ (Peak 4), the $\mathrm{CH}_{2}$ twisting at $1295 \mathrm{~cm}^{-1}$ (Peak 5), the $\mathrm{C}-\mathrm{O}$ stretching at $1289 \mathrm{~cm}^{-1}$ (Peak 6), the asymmetrical vibration of C-O-C at $1231 \mathrm{~cm}^{-1}$ (Peak 7), the $\mathrm{CH}_{2}$ twisting at $1189 \mathrm{~cm}^{-1}$ (Peak 8), the C-H bending at $1134 \mathrm{~cm}^{-1}$ (Peak 9), the combined vibration 
modes including C-C and C-O at $1103 \mathrm{~cm}^{-1}$ (Peak 10), and the stretching vibration of C-O at $1059 \mathrm{~cm}^{-1}$ (Peak 11). Compared with the spectrum of PVEfm, no additional peak or missing peak was found in the spectrum of NVEfm. The same result was found when a comparison between the spectra of PVEfm-B and NVEfm-B was made, implying that the chemical structure was not affected by the polarity of the applied electrospinning voltage. Compared with the spectrum of PVEfm, no additional or missing peak was found in the spectrum of PVEfm-B. Similarly, no additional or missing peak was observed when the spectra of NVEfm and NVEfm-B were compared. BTEAC may have totally evaporated with the solvent in air during the electrospinning process.

\subsection{Wettability of the PV-and NV-electrospun fibrous membranes}

Water contact angles of the flat solvent-cast PHBV film and the four groups of electrospun fibrous PHBV membranes (viz. PVEfm, PVEfm-B, NVEfm, and NVEfm-B) were measured and are shown in table 2. The contact angle of the PVEfm was similar to that of the NVEfm, provided that the membranes were electrospun at the same processing condition except the voltage polarity. However, the contact angle of either the PV- or NV-electrospun fibrous PHBV membrane was significantly higher than that of the solvent-cast PHBV film, suggesting that the hydrophobicity may increase with surface roughness which dramatically increases the number of contacting points between the water droplet and the material surface such that the boundary between them is not truly a solid-liquid interface. This result is in agreement with the water contact angle measurement results obtained by Ito et al. [40] and Sombatmankhong et al. [41], although they only investigated PV-electrospinning. Ito et al. reported that the water contact angle of the fibrous PHBV membrane (about $110^{\circ}$ ) was higher than that of the PHBV solvent-cast film (about $81^{\circ}$ ) while Sombatmankhong et al. also showed that the water contact angles of the electrospun fibrous PHBV, PHB and PHB/PHBV membranes ranged between $116^{\circ}$ and $122^{\circ}$, which were higher than that of the corresponding solvent-cast film $\left(68^{\circ}-75^{\circ}\right)$. However, the water droplets completely spread out on both PVEfm-B and NVEfm-B and no contact angle could be measured. As PVEfm-B and NVEfm-B exhibited fiber diameters in a submicron scale while PVEfm and NVEfm exhibited fiber diameters of a few 
microns, the results suggest that the reduction in fiber diameter improves the wettability of the membranes.

\subsection{Thermal analysis of the $P V$ - and $N V$-electrospun fibrous membranes}

Thermal properties of the solvent-cast PHBV films and the four groups of electrospun fibrous membranes (viz. PVEfm, PVEfm-B, NVEfm, and NVEfm-B) were investigated using DSC, and their typical thermograms are shown in figure 8 . The numerical values corresponding to thermal transition and crystallinity are listed in table 3 . The curve in figure $8(B)$ is the thermogram of solvent-cast PHBV film in a larger scale than that in figure $8(A)$, which clearly illustrates the thermal behaviour of PHBV in the solvent-cast film state. As shown in figure $8(B)$, two melting peaks at approximately $171.3^{\circ} \mathrm{C}$ and $151.7^{\circ} \mathrm{C}$ are observed, though the shoulder peak at $151.7^{\circ} \mathrm{C}$ cannot be easily seen in figure $8(A)$. The multiple melting peaks can be attributed to the melting transition of recrystallized PHBV crystallite during the heating process [42]. The crystallinity of electrospun fibrous PHBV membranes was much greater than that of solvent-cast PHBV films. The entanglement of PHBV molecules to each other during crystallization should be the reason for the relatively low crystallinity of PHBV solvent-cast films. Although entanglement of PHBV molecules still occurred in electrospun fibers, the molecule entanglement was at the micron / submicron scale and the molecular entanglement was oriented along the fiber direction due to the spatial confinement, resulting in higher crystallinity. All groups of electrospun PHBV fibrous membranes exhibited similar crystallinity, suggesting that the orientation of polymer molecules wound not be significantly influenced by the polarity of the applied electrospinning voltage or the addition of surfactant.

\subsection{Tensile properties of the PV-and NV-electrospun fibrous membranes}

The tensile properties ( $\sigma_{\mathrm{UTS}}, E$, and $\varepsilon$ ) of the four groups of electrospun PHBV fibrous membranes (viz. PVEfm, PVEfm-B, NVEfm, and NVEfm-B) were also evaluated in order to determine the effect of applied voltage polarity and surfactant addition. The stress-strain curves for these four groups of fibrous 
membranes are shown in figure 9. The ultimate tensile strength and stiffness of the four groups of fibrous membranes were found to be similar. When developing electrospun fibrous membranes for tissue engineering scaffold applications, the mechanical property of the membranes should be one of the major considerations because a reliable fibrous scaffold should be strong enough for handling, sterilization, and supporting cell attachment as well as the subsequent cellular activities. In our unpublished studies, both PVEfm and PVEfm-B were found to be robust enough for routine culture of osteoblasts. The present study showed that the tensile strength and stiffness of NVEfm and NVEfm-B were similar to that of PVEfm and PVEfm-B, implying that NV-electrospinning could also be employed for developing scaffolds for tissue engineering applications. Interestingly, the elongation at break could be significantly increased when the fiber diameters were reduced to the submicron level by the addition of surfactant, especially for PV-electrospinning. As PVEfm-B and NVEfm-B had fiber diameters of a few hundred nanometers only while PVEfm and NVEfm exhibited fiber diameters of a few microns, fibers with smaller diameters would be desirable if a tough fibrous membrane is required.

The biocompatibility of PV-electrospun PHBV fibers has been evaluated. Cytotoxicity tests were conducted using mouse fibroblast L929 cell line through cell culture. As shown in figure 10, the viability of the L929 cells cultured with an extraction medium containing the PV-electrospun PHBV fibers was comparable to that of the cells cultured with the medium from the control, implying no or negligible cytotoxicity of these fibrous membranes. The mouse fibroblast L929 cell line is commonly used for cytotoxicity evaluation, which is a convenient, sensitive, and standardized biomaterial evaluation method to determine whether the biomaterial is cytotoxic or whether it releases substantial amounts of harmful substances that significantly affect the normal cell function. It is used to determine whether the material, no matter it is intended as a permanent implant or a temporary scaffold, is cytotoxic before other biological evaluations can be made. Neamnark et al. made hexanoyl chitosan fibrous scaffolds by electrospinning and cytotoxicity evaluation of the scaffolds was conducted also using mouse fibroblasts (L929). Because of the high viability of L929 cells, they concluded that the materials were non-cytotoxic and did not release harmful substances [43]. Similarly, Skotak et al. conducted cytotoxicity tests using 
L929 cells on electrospun ${ }_{L}$-lactide modified chitosan fibers and showed that the developed material was a promising material for tissue engineering purposes [44]. Jin et al. fabricated photocrosslinked chitosanbased nanofibers and the subsequent cell culture experiments using mouse fibroblasts (L929) showed that the cells exhibited their characteristic spindle morphology. The comparable amounts of viable cells seeded with the extraction medium and seeded with the culture medium of the control after preset culture

time hence indicated a non-cytotoxic response of the samples tested [45]. Further biological assessment of the PV-electrospun PHBV fibers was conducted through cell culture studies using a human osteoblastlike cell line (SaOS-2), which is a non-transformed cell line. SaOS-2 can not only exhibit various osteoblastic features and replicate very rapidly in vitro but also demonstrate a complete series of cellular events for forming bone tissue. The SaOS-2 cells were found to attach, spread, proliferate and express alkaline phosphatase (ALP) activity on the PV-electrospun PHBV fibrous membranes. After one week cell culture, the cells expanded and spread randomly in all directions on PHBV fibers [figure 11(A)]. After two week cell culture, the cells not only expanded and spread on the fibers but also formed numerous filopodia [figure 11(B)], which facilitated cell attachment and migration. These cellular events are important because cell attachment is the first cellular event during the whole tissue regeneration process. Without cell attachment, the cells alone cannot become tissues. Sombatmankhong et al. also found that SaOS-2 cells adhered well on their PHBV fibrous scaffolds [41]. The biological evaluation of NV-electrospun fibers is currently conducted. No or negligible cytotoxicity and desirable cell responses are expected.

\section{Conclusions}

The current study investigated PV-electrospinning and NV-electrospinning and fibrous membranes of PHBV with different ranges of fiber diameters were successfully produced. In both PV-electrospinning and NV-electrospinning, it was found that the fiber diameter generally increased with increasing solution concentration and increasing inner diameter but decreased with increasing working distance while the solution feeding rate did not significantly affect the fiber diameter. However, the fiber diameter increased 
with increasing PV but decreased with increasing NV. The addition of BTEAC drastically reduced fiber diameters to the submicron range. Both PV- and NV-electrospun PHBV fibrous membranes exhibited similar chemical structures. The PHBV solvent-cast film exhibited much lower water contact angle than the electrospun PHBV fibrous membranes. Polarity of the applied voltage did not significantly affect the water contact angle of electrospun fibrous membranes. The PHBV solvent-cast film exhibited lower crystallinity than electrospun fibrous PHBV membranes but the melting peaks of fibrous membranes were not significantly affected by the polarity of the applied voltage or the addition of BTEAC. No matter whether BTEAC was added, both PV- and NV-electrospun fibrous PHBV membranes exhibited similar ultimate tensile strength and stiffness, although the addition of BTEAC significantly improved the elongation at break. These findings should be very useful for developing fibrous tissue engineering scaffolds using either or both PV-electrospinning and NV-electrospinning.

\section{Acknowledgements}

This work was supported by a GRF grant (HKU 7176/08E) from the Research Grants Council of Hong Kong. The authors acknowledge the assistance provided by technical staff in the Department of Mechanical Engineering of The University of Hong Kong. 


\section{References}

[1] Bhardwaj N and Kundu S C 2010 Electrospinning: a fascinating fiber fabrication technique Biotechnol. Adv. 28 325-47

[2] Liao S, Chan C K and Ramakrishna S 2010 Electrospun nanofibers: work for medicine? Signal, Image and Video Processing 4 29-33

[3] Kalayci V E, Patra P K, Kim Y K, Ugbolue S C and Warner S B 2005 Charge consequences in electrospun polyacrylonitrile (PAN) nanofibers Polymer 46 7191-200

[4] Greiner A and Wendorff J H 2007 Electrospinning: a fascinating method for the preparation of ultrathin fibers Angew. Chem-Ger. Edit. 46 5670-703

[5] Casper C L, Yamaguchi N, Kiick K L and Rabolt J F 2005 Functionalizing electrospun fibers with biologically relevant macromolecules Biomacromolecules 6 1998-2007

[6] Mit-Uppatham C, Nithitanakul M and Supaphol P 2004 Effects of solution concentration, emitting electrode polarity, solvent type, and salt addition on electrospun polyamide- 6 fibers: a preliminary report Macromol. Sy. 216 293-9

[7] Schreuder-Gibson H, Gibson P, Tsai P P, Gupta P and Wilkes G L 2004 Cooperative charging effects of fibers from electrospinning of electrically dissimilar polymers International Nonwovens Journal 13 39-45

[8] Stanger J, Tucker N, Wallace A, Larsen N, Staiger M and Reeves R 2009 The effect of electrode configuration and substrate material on the mass deposition rate of electrospinning $J$. Appl. Polym. Sci. 112 1729-37

[9] Yang Y, Jia Z, Li Q and Guan Z 2006 Experimental investigation of the governing parameters in the electrospinning of polyethylene oxide solution IEEE T. Dielect. El. In. 13 580-5

[10] Lee C H, Shin H J, Cho I H, Kang Y-M, Kim I A, Park K-D and Shin J-W 2005 Nanofiber alignment and direction of mechanical strain affect the ECM production of human ACL fibroblast Biomaterials 26 1261-70

[11] Xie J, MacEwcm M R, Willerth S M, Li X, Moran D W, Sakiyama-Elbert S E and Xia Y 2009 Conductive core-sheath nanofibers and their potential application in neural tissue engineering Adv. Funct. Mater. 19 2312-8

[12] Riboldi S A, Sadr N, Pigini L, Neuenschwander P, Simonet M, Mognol P, Sampaolesi M, Cossu $\mathrm{G}$ and Mantero S 2008 Skeletal myogenesis on highly orientated microfibrous polyesterurethane scaffolds J. Biomed. Mater. Res. A 84A 1094-101

[13] Drilling S, Gaumer J and Lannutti J 2009 Fabrication of burst pressure competent vascular grafts via electrospinning: effects of microstructure $J$. Biomed. Mater. Res. A 88A 923-34

[14] Theron S A, Zussman E and Yarin A L 2001 Electrostatic field-assisted alignment of electrospun nanofibers Nanotechnology 12 384-90 
[15] Lin T, Wang H X, Wang H M and Wang X G 2004 The charge effect of cationic surfactants on the elimination of fibre beads in the electrospinning of polystyrene Nanotechnology 15 1375-81

[16] Arumugam G K, Khan S and Heiden P A 2009 Comparison of the effects of an ionic liquid and other salts on the properties of electrospun fibers, 2 - poly(vinyl alcohol) Macromol. Mater. Eng. $29445-53$

[17] Wang S-Q, He J-H and Xu L 2008 Non-ionic surfactants for enhancing electrospinability and for the preparation of electrospun nanofibers Polym. Int. 57 1079-82

[18] Chung T-H, Wu S-H, Yao M, Lu C-W, Lin Y-S, Hung Y, Mou C-Y, Chen Y-C and Huang D-M 2007 The effect of surface charge on the uptake and biological function of mesoporous silica nanoparticles in 3T3-L1 cells and human mesenchymal stem cells Biomaterials 28 2959-66

[19] Schneider G B, English A, Abraham M, Zaharias R, Stanford C and Keller J 2004 The effect of hydrogel charge density on cell attachment Biomaterials 25 3023-8

[20] Catalani L H, Collins G and Jaffe M 2007 Evidence for molecular orientation and residual charge in the electrospinning of poly(butylene terephthalate) nanofibers Macromolecules 40 1693-7

[21] Lovera D, Bilbao C, Schreier P, Kador L, Schmidt H-W and Altstädt V 2009 Charge storage of electrospun fiber mats of poly(phenylene ether)/polystyrene blends Polym. Eng. Sci. 49 2430-9

[22] Xin H Z, Seng K G, Wang C-H and Tong Y W 2007 Proteins combination on PHBV microsphere scaffold to regulate Hep3B cells activity and functionality: a model of liver tissue engineering system J. Biomed. Mater. Res. A 83A 606-16

[23] Liu J, Zhao B, Zhang Y, Lin Y, Hu P and Ye C 2010 PHBV and predifferentiated human adipose-derived stem cells for cartilage tissue engineering J. Biomed. Mater. Res. A 94A 603-10

[24] Tong H W and Wang M 2007 Electrospinning of aligned biodegradable polymer fibers and composite fibers for tissue engineering applications J. Nanosci. Nanotechno. 7 3834-40

[25] Tong H W, Wang M, Li Z, Lam W-M and Lu W W 2009 Electrospinning of surface-porous fibers and in vitro biological study of these fibers Proceedings of the World Congress on Bioengineering 2009, Hong Kong

[26] Tong H W and Wang M 2007 Effects of processing parameters on the morphology and size of electrospun PHBV micro- and nano-fibers Key Eng. Mat. 334-335 II 1233-6

[27] Rosa D S, Lotto N T, Lopes D R and Guedes C G F 2004 The use of roughness for evaluating the biodegradation of poly- $\beta$-(hydroxybutyrate) and poly- $\beta$-(hydroxybutyrate-co- $\beta$-valerate) Polym. Test. 23 3-8

[28] Katti D S, Robinson K W, Frank K K and Cato T L 2004 Bioresorbable nanofiber-based systems for wound healing and drug delivery: optimization of fabrication parameters J. Biomed. Mater. Res. B 70B 286-96

[29] Tan S H, Inai R, Kotaki M and Ramakrishna S 2005 Systematic parameter study for ultra-fine fiber fabrication via electrospinning process Polymer 46 6128-34 
[30] Cui W, Li X, Zhou S and Weng J 2007 Investigation on process parameters of electrospinning system through orthogonal experimental design J. Appl. Polym. Sci. 103 3105-12

[31] Baker S C, Atkin N, Gunning P A, Granville N, Wilson K, Wilson D and Southgate J 2006 Characterisation of electrospun polystyrene scaffolds for three-dimensional in vitro biological studies Biomaterials 27 3136-46

[32] Demir M M, Yilgor I, Yilgor E and Erman B 2002 Electrospinning of polyurethane fibers Polymer 43 3303-9

[33] Fennessey S F and Farris R J 2004 Fabrication of aligned and molecularly oriented electrospun polyacrylonitrile nanofibers and the mechanical behavior of their twisted yarns Polymer $\mathbf{4 5}$ 421725

[34] Buchko C J, Chen L C, Shen Y and Martin D C 1999 Processing and microstructural characterization of porous biocompatible protein polymer thin films Polymer $\mathbf{4 0}$ 7397-407

[35] Kidoaki S, Kwon I K and Matsuda T 2005 Mesoscopic spatial designs of nano- and microfiber meshes for tissue-engineering matrix and scaffold based on newly devised multilayering and mixing electrospinning techniques Biomaterials 26 37-46

[36] Li Q, Yang Y, Jia Z and Guan Z 2007 Experimental investigation of the effect of processing parameters on the formation of electrospun polyethylene oxide nanofibers High Voltage Engineering 33 186-9

[37] Lyons J, Li C and Ko F 2004 Melt-electrospinning part I: processing parameters and geometric properties Polymer 45 7597-603

[38] Mo X M, Xu C Y, Kotaki M and Ramakrishna S 2004 Electrospun P(LLA-CL) nanofiber: a biomimetic extracellular matrix for smooth muscle cell and endothelial cell proliferation Biomaterials 25 1883-90

[39] Yördem O S, Papila M and Menceloglu Y Z 2008 Effects of electrospinning parameters on polyacrylonitrile nanofiber diameter: an investigation by response surface methodology Mater. Design 29 34-44

[40] Ito Y, Hasuda H, Kamitakahara M, Ohtsuki C, Tanihara M, Kang I-K and Kwon O H 2005 A composite of hydroxyapatite with electrospun biodegradable nanofibers as a tissue engineering material J. Biosci. Bioeng. 100 43-9

[41] Sombatmankhong K, Sanchavanakit N, Pavasant P and Supaphol P 2007 Bone scaffolds from electrospun fiber mats of poly(3-hydroxybutyrate), poly(3-hydroxybutyrate-co-3hydroxyvalerate) and their blend Polymer 48 1419-27

[42] Chan K H K, Wong S Y, Li X, Zhang Y Z, Lim P C, Lim C T, Kotaki M and He C B 2009 Effect of molecular orientation on mechanical property of single electrospun fiber of poly[(R)-3hydroxybutyrate-co-(R)-3-hydroxyvalerate] J. Phys. Chem. B 113 13179-85

[43] Neamnark A, Sanchavanakit N, Pavasant P, Rujiravanit R and Supaphol P 2008 In vitro biocompatibility of electrospun hexanoyl chitosan fibrous scaffolds towards human keratinocytes and fibroblasts Eur. Polym. J. 44 2060-7 
[44] Skotak M, Leonov A P, Larsen G, Noriega S and Subramanian A 2008 Biocompatible and biodegradable ultrafine fibrillar scaffold materials for tissue engineering by facile grafting of $\mathrm{L}_{\mathrm{-}}$ lactide onto chitosan Biomacromolecules 9 1902-8

[45] Jin Y, Yang D, Zhou Y, Ma G and Nie J 2008 Photocrosslinked electrospun chitosan-based biocompatible nanofibers J. Appl. Polym. Sci. 109 3337-43 


\section{List of Tables}

Table $1 \quad$ Studies on negative voltage electrospinning

Table 2 Water contact angles of PHBV solvent-cast film and electrospun fibrous membranes

Table 3 Thermal properties and apparent crystallinity of PHBV solvent-cast film and electrospun fibrous membranes 
Table 1 Studies on negative voltage electrospinning

\begin{tabular}{lll}
\hline Polymer & Major finding & Reference \\
\hline PAN & $\begin{array}{l}\text { The diameter distribution of the fibers electrospun using } \\
\text { NVs was narrower than that of PVs. }\end{array}$ & Kalayci et al. [3] \\
PEG & $\begin{array}{l}\text { The NV-electrospun fibers had diameters ranging from } \\
\text { approximately 100 to } 400 \mathrm{~nm} \text { but fibers could not be } \\
\text { electrospun using PV. }\end{array}$ & Casper et al. [5] \\
& $\begin{array}{l}\text { The diameter of NV-electrospun fibers was larger than } \\
\text { that of PV-electrospun fibers. }\end{array}$ & $\begin{array}{l}\text { Mit-uppatham et al. } \\
\text { PA-6 }\end{array}$ \\
PAN and & $\begin{array}{l}\text { Multilayered structures consisting of PV-electrospun } \\
\text { PS }\end{array}$ & $\begin{array}{l}\text { SAN fibers and NV-electrospun PS fibers were made. } \\
\text { Pl. [7] }\end{array}$ \\
PVA & $\begin{array}{l}\text { Fiber deposition rate of PV-electrospinning was higher } \\
\text { than that of NV-electrospinning. }\end{array}$ & Stanger et al. [8] \\
PEO & $\begin{array}{l}\text { The diameter of NV-electrospun fibers was larger than } \\
\text { that of PV-electrospun fibers. }\end{array}$ & Yang et al. [9] \\
\hline
\end{tabular}

PV: positive voltage; NV: negative voltage; PAN: polyacrylonitrile; PEG: poly(ethylene glycol); PA-6: polyamide-6; PS: polystyrene; PVA: poly(vinyl alcohol); PEO: polyethylene oxide 
Table 2 Water contact angles of PHBV solvent-cast film and electrospun fibrous membranes

\begin{tabular}{ll}
\hline Material & Contact angle $\left(^{\circ}\right)$ \\
\hline $\begin{array}{l}\text { PHBV solvent-cast flat film } \\
\text { PV-electrospun PHBV fibrous membrane from PHBV } \\
\text { solutions without BTEAC (PVEfm) }\end{array}$ & $68.4 \pm 5.2$ \\
$\begin{array}{l}\text { PV-electrospun PHBV fibrous membrane from PHBV } \\
\text { solutions with BTEAC (PVEfm-B) }\end{array}$ & $104.2 \pm 3.1$ \\
$\begin{array}{l}\text { NV-electrospun PHBV fibrous membrane from PHBV } \\
\text { solutions without BTEAC (NVEfm) }\end{array}$ & Not measurable. \\
$\begin{array}{l}\text { NV-electrospun PHBV fibrous membrane from PHBV } \\
\text { solutions with BTEAC (NVEfm-B) }\end{array}$ & $104.8 \pm 2.9$ \\
\hline
\end{tabular}


Table 3 Thermal properties and apparent crystallinity of PHBV solvent-cast film and electrospun fibrous membranes

\begin{tabular}{llll}
\hline Material & $\mathrm{T}_{\mathrm{m}}\left({ }^{\circ} \mathrm{C}\right)$ & $\Delta \mathrm{H}_{\mathrm{f}}(\mathrm{J} / \mathrm{g})$ & $\mathrm{X}_{\mathrm{c}}(\%)$ \\
\hline $\begin{array}{l}\text { PHBV solvent-cast film } \\
\text { PV-electrospun PHBV fibrous membrane }\end{array}$ & $171.3(151.7)^{\mathrm{a}}$ & 37.2 & 25.5 \\
$\begin{array}{l}\text { from PHBV solutions without BTEAC } \\
\text { (PVEfm) }\end{array}$ & 165.8 & 68.4 & 46.8 \\
$\begin{array}{l}\text { PV-electrospun PHBV fibrous membrane } \\
\text { from PHBV solutions with BTEAC }\end{array}$ & 163.5 & 67.0 & 45.9 \\
$\begin{array}{l}\text { (PVEfm-B) } \\
\text { NV-electrospun PHBV fibrous membrane } \\
\text { from PHBV solutions without BTEAC } \\
\text { (NVEfm) }\end{array}$ & & & \\
$\begin{array}{l}\text { NV-electrospun PHBV fibrous membrane } \\
\text { from PHBV solutions with BTEAC } \\
\text { (NVEfm-B) }\end{array}$ & 167.9 & 75.5 & 51.7 \\
\hline
\end{tabular}

$\mathrm{T}_{\mathrm{m}}$ : apparent melting peak temperature; $\Delta \mathrm{H}_{\mathrm{f}}$ : apparent enthalpy of fusion; $\mathrm{X}_{\mathrm{c}}$ : crystallinity index;

${ }^{\text {a }}$ Shoulder peak of melting transition 


\section{List of Figures}

Figure 1 Electrospun PHBV fibers obtained using different needle diameters: $(A)$ at $0.4 \mathrm{~mm}$ inner diameter by PV-electrospinning, $(B)$ at $0.7 \mathrm{~mm}$ inner diameter by PV-electrospinning, $(C)$ at $0.4 \mathrm{~mm}$ inner diameter by NV-electrospinning, $(D)$ at $0.7 \mathrm{~mm}$ inner diameter by NVelectrospinning, and $(E)$ relationship between needle inner diameter and average fiber diameter for electrospun PHBV fibers. (a denotes PV-electrospinning; • denotes NVelectrospinning; * denotes $p<0.05)$

Figure 2 Electrospun PHBV fibers obtained using different solution feeding rates: $(A)$ at $1 \mathrm{ml} / \mathrm{h}$ by PVelectrospinning, $(B)$ at $7 \mathrm{ml} / \mathrm{h}$ by $\mathrm{PV}$-electrospinning, $(C)$ at $1 \mathrm{ml} / \mathrm{h}$ by $\mathrm{NV}$-electrospinning, $(D)$ at $7 \mathrm{ml} / \mathrm{h}$ by $\mathrm{NV}$-electrospinning, and $(E)$ relationship between solution feeding rate and average fiber diameter for electrospun PHBV fibers. (a denotes PV-electrospinning; denotes NV-electrospinning)

Figure 3 Electrospun PHBV fibers obtained using different applied voltages: $(A)$ at $15 \mathrm{kV}$ by PVelectrospinning, $(B)$ at $25 \mathrm{kV}$ by $\mathrm{PV}$-electrospinning, $(C)$ at $-15 \mathrm{kV}$ by $\mathrm{NV}$-electrospinning, $(D)$ at $-25 \mathrm{kV}$ by $\mathrm{NV}$-electrospinning, and $(E)$ relationship between applied voltage and average fiber diameter for electrospun PHBV fibers. (a denotes PV-electrospinning; denotes NV-electrospinning; * denotes $p<0.05)$

Figure 4 Electrospun PHBV fibers obtained using different working distances: $(A)$ at $15 \mathrm{~cm}$ by PVelectrospinning, $(B)$ at $25 \mathrm{~cm}$ by PV-electrospinning, $(C)$ at $15 \mathrm{~cm}$ by NV-electrospinning, $(D)$ at $25 \mathrm{~cm}$ by NV-electrospinning, and $(E)$ relationship between working distance and average fiber diameter for electrospun PHBV fibers. (a denotes PV-electrospinning; denotes NV-electrospinning; * denotes $p<0.05)$ 
Figure 5 Electrospun PHBV fibers obtained using different solution concentrations: $(A)$ at $15 \% \mathrm{w} / \mathrm{v}$ by PV-electrospinning, $(B)$ at $25 \% \mathrm{w} / \mathrm{v}$ by PV-electrospinning, $(C)$ at $15 \% \mathrm{w} / \mathrm{v}$ by $\mathrm{NV}-$ electrospinning, $(D)$ at $25 \% \mathrm{w} / \mathrm{v}$ by NV-electrospinning, and $(E)$ relationship between solution concentration and average fiber diameter for electrospun PHBV fibers. ( $\square$ denotes PV-electrospinning; • denotes NV-electrospinning; * denotes $p<0.05$ )

Figure 6 Electrospun PHBV fibers obtained using different BTEAC concentrations: $(A)$ at $0 \mathrm{wt} \%$ by PV-electrospinning, $(B)$ at $2 \mathrm{wt} \%$ by PV-electrospinning, $(C)$ at $0 \mathrm{wt} \%$ by $\mathrm{NV}-$ electrospinning, $(D)$ at $2 \mathrm{wt} \%$ by NV-electrospinning, and $(E)$ relationship between BTEAC concentration and average fiber diameter for electrospun PHBV fibers. ( $\square$ denotes PVelectrospinning; • denotes NV-electrospinning; * denotes $p<0.05 ; * *$ denotes $p<0.01$ )

Figure 7 FTIR spectra of the four groups of fibrous PHBV membranes: PV-electrospun fibrous membrane from PHBV solutions without BTEAC (PVEfm), PV-electrospun fibrous membranes from PHBV solutions with BTEAC (PVEfm-B), NV-electrospun fibrous membrane from PHBV solutions without BTEAC (NVEfm), and NV-electrospun fibrous membranes from PHBV solutions with BTEAC (NVEfm-B)

Figure 8 DSC thermograms: $(A)$ PHBV solvent-cast film and the four groups of electrospun fibrous membranes, $(B)$ the thermogram for PHBV solvent-cast film showing the shoulder peak

Figure 9 Stress-strain curves for the four groups of fibrous PHBV membranes: PV-electrospun fibrous membranes from PHBV solutions without BTEAC (PVEfm), PV-electrospun fibrous membranes from PHBV solutions with BTEAC (PVEfm-B), NV-electrospun fibrous membranes from PHBV solutions without BTEAC (NVEfm), and NV-electrospun fibrous membranes from PHBV solutions with BTEAC (NVEfm-B) 
Figure 10 Morphology of L929 cells: $(A)$ after cell culture with an extraction medium containing PVelectrospun PHBV fibers, $(B)$ after cell culture with the culture medium of the control

Figure 11. Morphology of SaOS-2 cells seeded on electrospun PHBV fibers after different cell culture times: $(A) 1$ week, $(B) 2$ weeks 

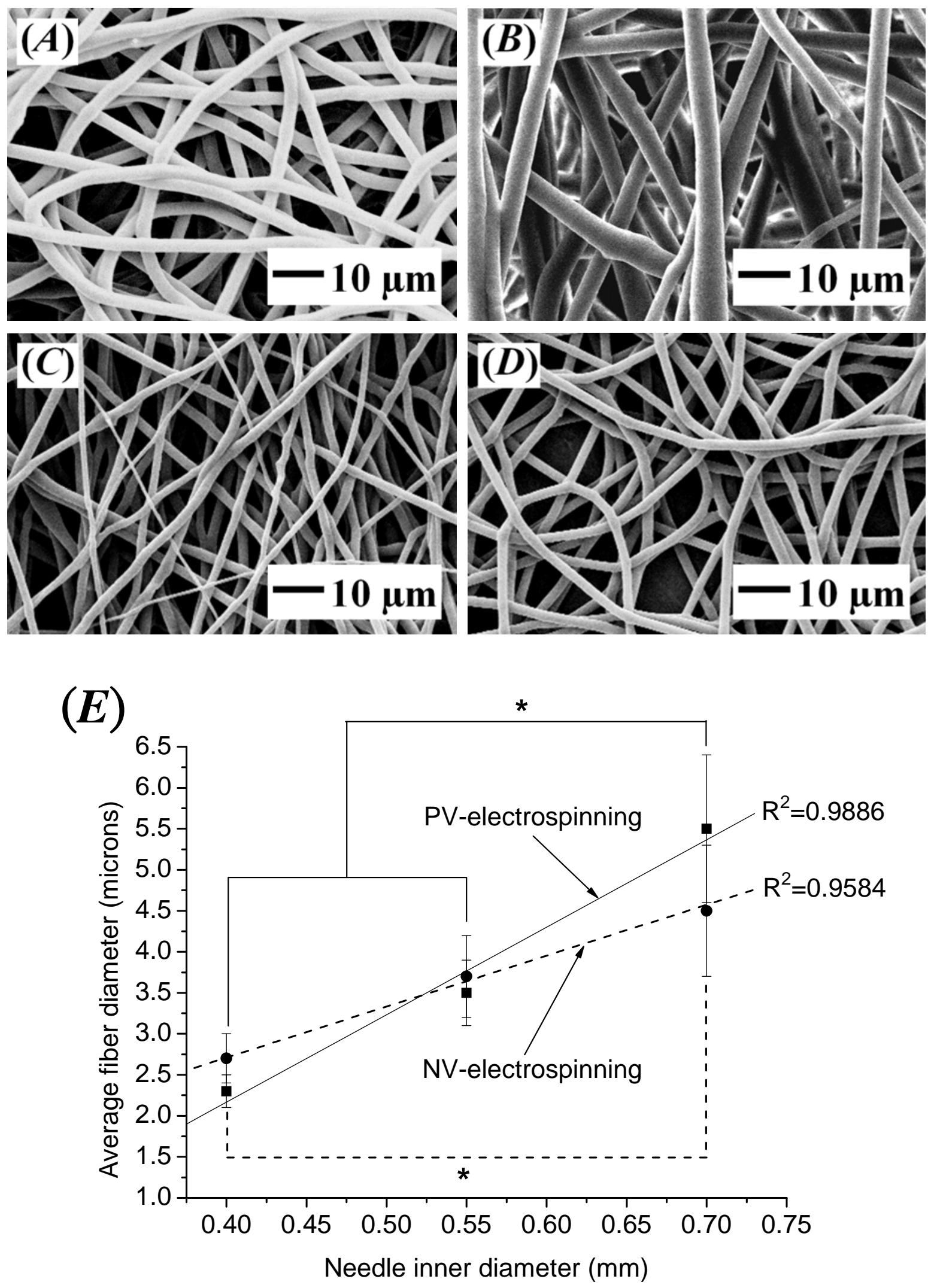

Figure 1. Electrospun PHBV fibers obtained using different needle diameters: $(A)$ at $0.4 \mathrm{~mm}$ inner diameter by PV-electrospinning, $(B)$ at $0.7 \mathrm{~mm}$ inner diameter by PV-electrospinning, $(C)$ at $0.4 \mathrm{~mm}$ inner diameter by NV-electrospinning, $(D)$ at $0.7 \mathrm{~mm}$ inner diameter by NV-electrospinning, and $(E)$ relationship between needle inner diameter and average fiber diameter for electrospun PHBV fibers. ( denotes PV-electrospinning; • denotes NV-electrospinning; * denotes $p<0.05$ ) 

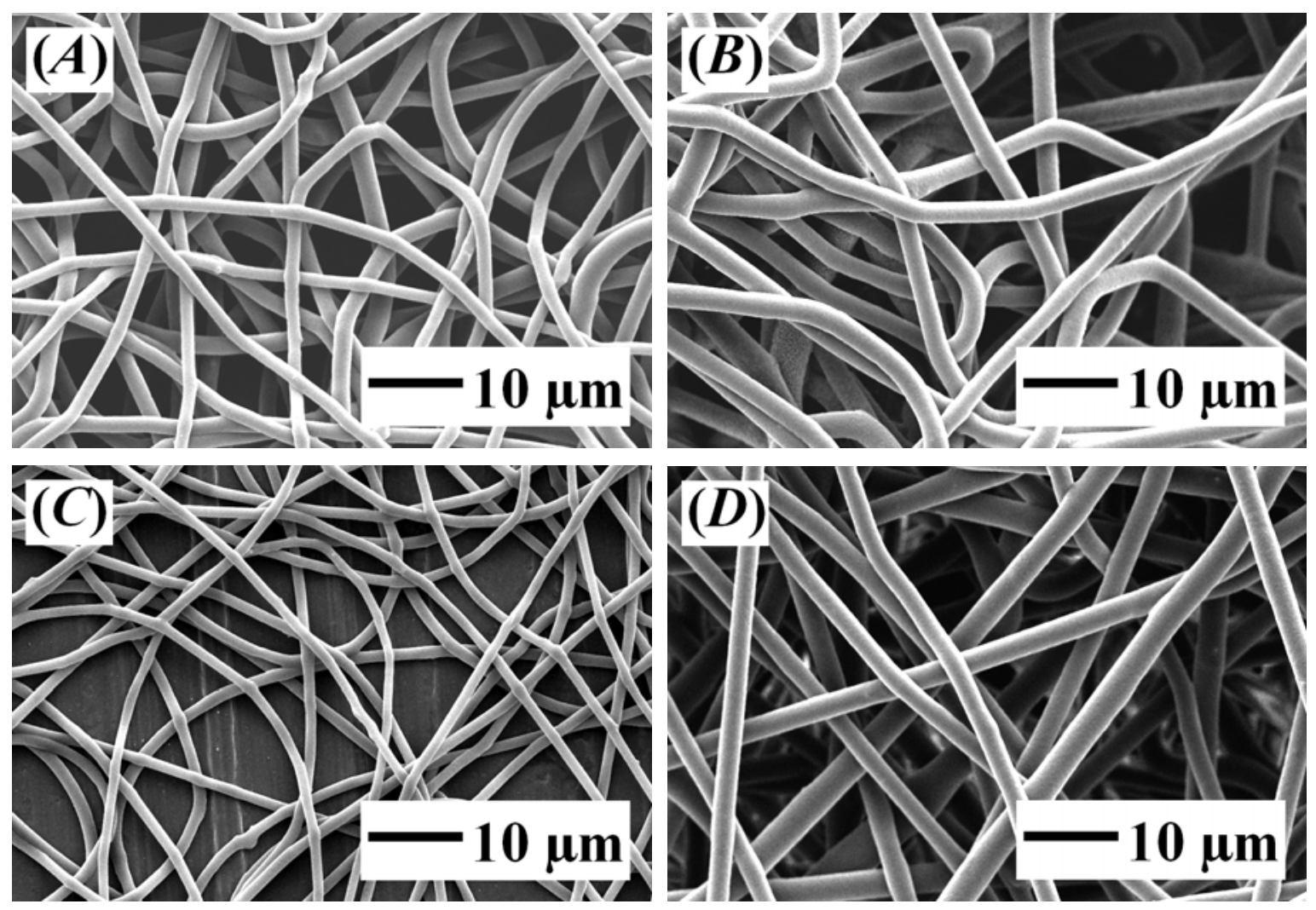

$(\boldsymbol{E})$

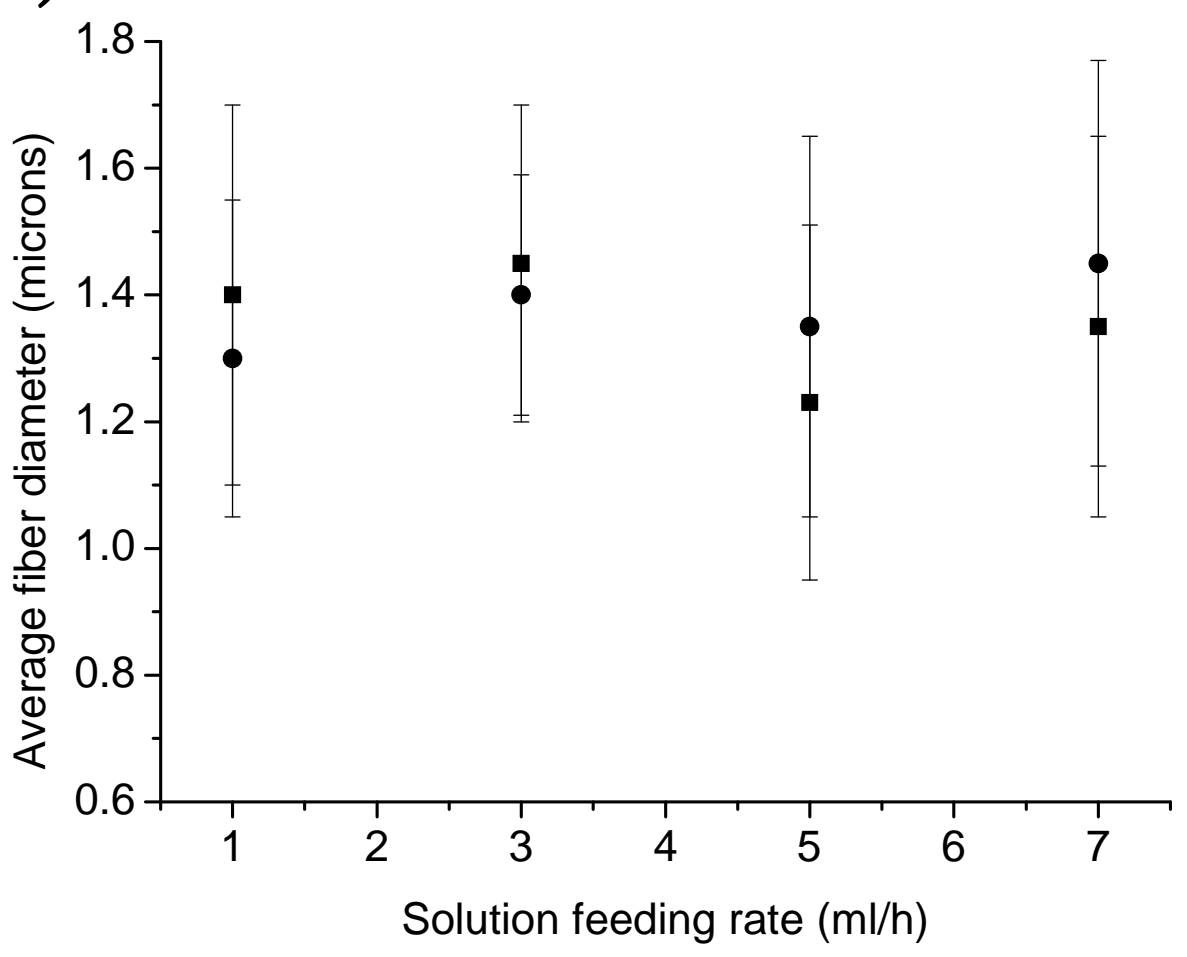

Figure 2. Electrospun PHBV fibers obtained using different solution feeding rates: $(A)$ at $1 \mathrm{ml} / \mathrm{h}$ by PV-electrospinning, $(B)$ at $7 \mathrm{ml} / \mathrm{h}$ by PV-electrospinning, $(C)$ at $1 \mathrm{ml} / \mathrm{h}$ by NV-electrospinning, $(D)$ at $7 \mathrm{ml} / \mathrm{h}$ by NV-electrospinning, and $(E)$ relationship between solution feeding rate and average fiber diameter for electrospun PHBV fibers. ( $\bullet$ denotes PV-electrospinning; $\bullet$ denotes NV-electrospinning) 

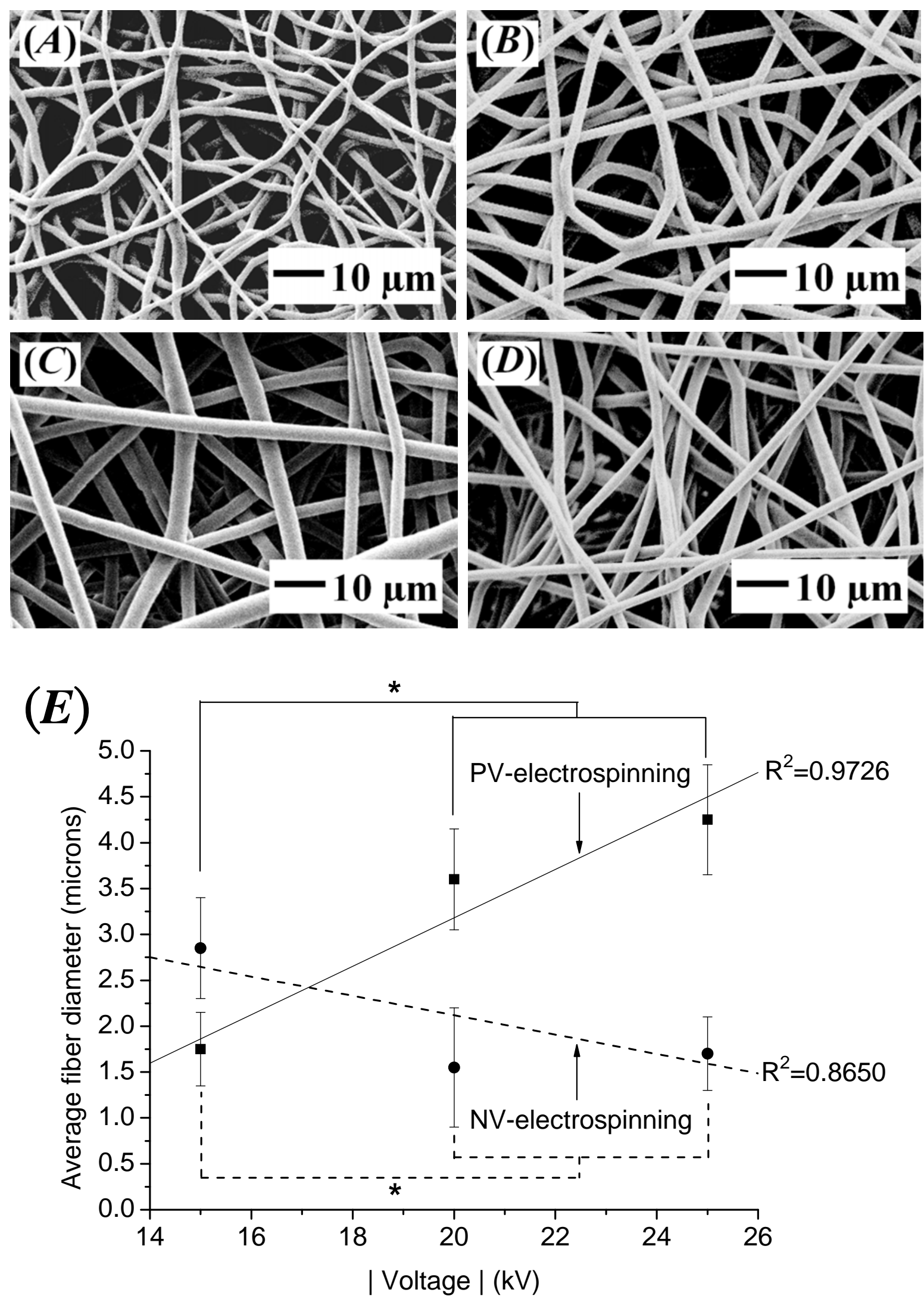

Figure 3. Electrospun PHBV fibers obtained using different applied voltages: $(A)$ at $15 \mathrm{kV}$ by PVelectrospinning, $(B)$ at $25 \mathrm{kV}$ by PV-electrospinning, $(C)$ at $-15 \mathrm{kV}$ by NV-electrospinning, $(D)$ at -25 $\mathrm{kV}$ by NV-electrospinning, and $(E)$ relationship between applied voltage and average fiber diameter for electrospun PHBV fibers. ( - denotes PV-electrospinning; • denotes NV-electrospinning; * denotes $p<0.05)$ 

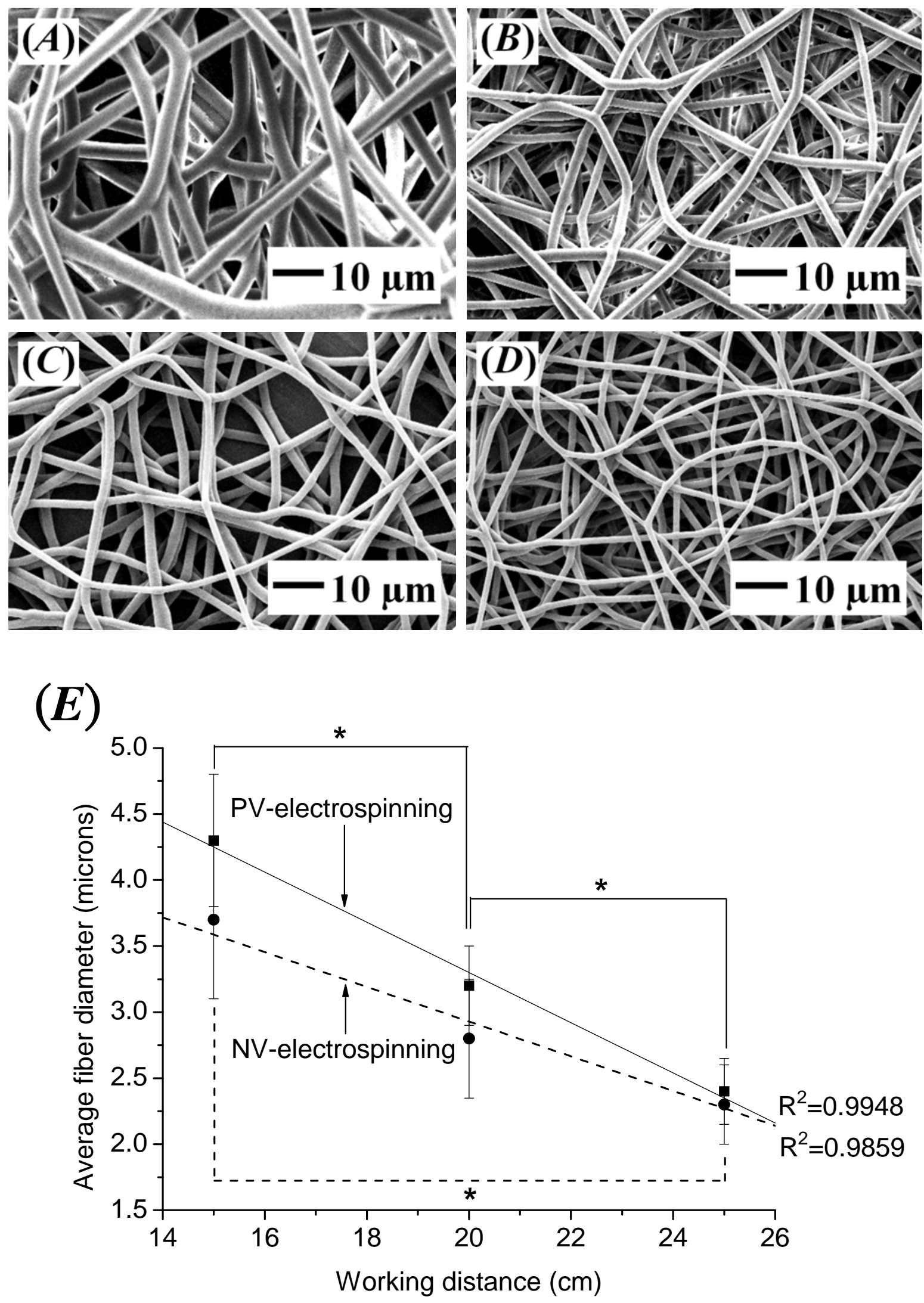

Figure 4. Electrospun PHBV fibers obtained using different working distances: $(A)$ at $15 \mathrm{~cm}$ by PVelectrospinning, $(B)$ at $25 \mathrm{~cm}$ by PV-electrospinning, $(C)$ at $15 \mathrm{~cm}$ by NV-electrospinning, $(D)$ at 25 $\mathrm{cm}$ by NV-electrospinning, and $(E)$ relationship between working distance and average fiber diameter for electrospun PHBV fibers. ( - denotes PV-electrospinning; • denotes NV-electrospinning; * denotes $p<0.05)$ 

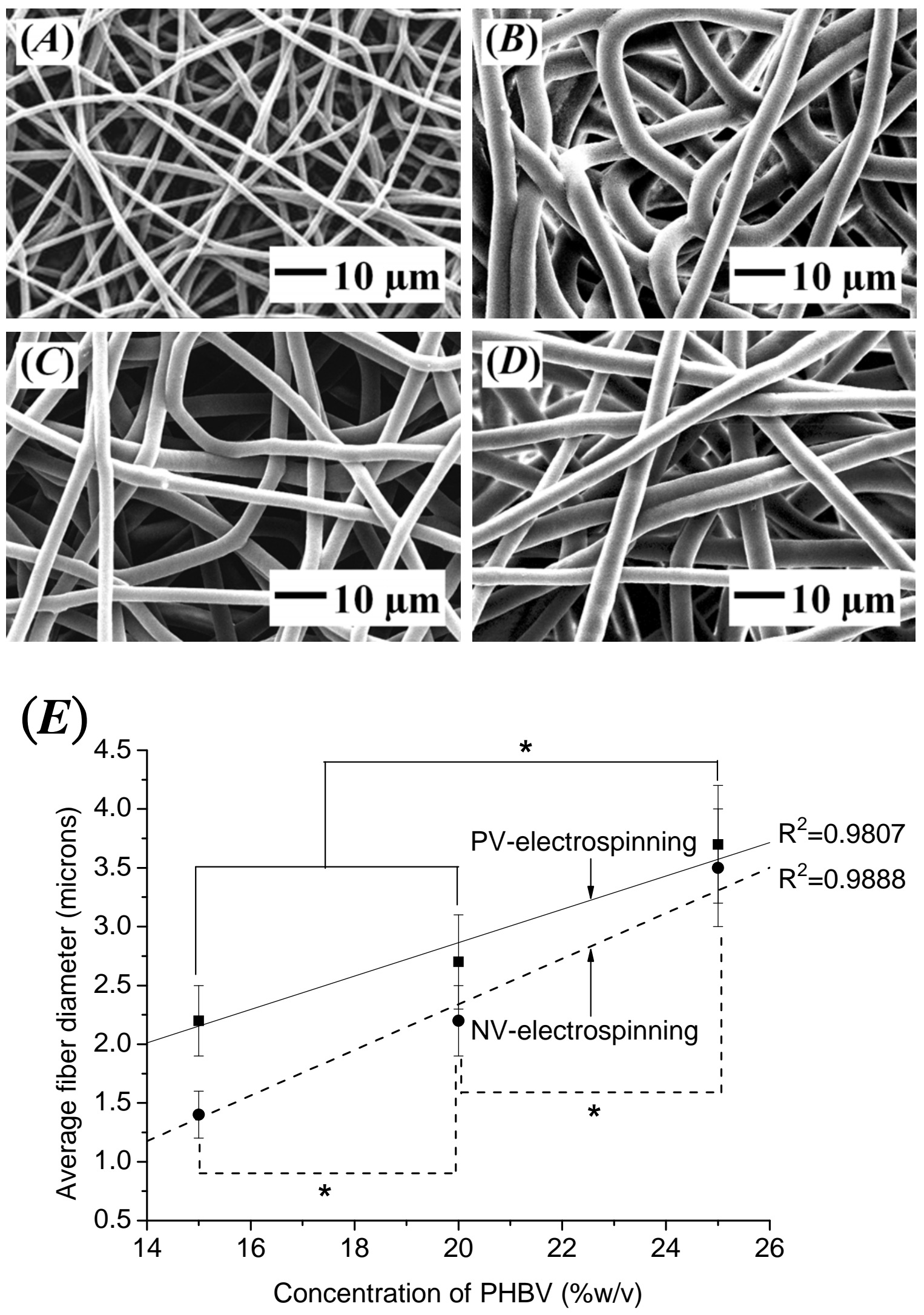

Figure 5. Electrospun PHBV fibers obtained using different solution concentrations: $(A)$ at $15 \% \mathrm{w} / \mathrm{v}$ by PV-electrospinning, $(B)$ at $25 \% \mathrm{w} / \mathrm{v}$ by PV-electrospinning, $(C)$ at $15 \% \mathrm{w} / \mathrm{v}$ by NV-electrospinning, $(D)$ at $25 \% \mathrm{w} / \mathrm{v}$ by NV-electrospinning, and $(E)$ relationship between solution concentration and average fiber diameter for electrospun PHBV fibers. ( denotes PV-electrospinning; $\bullet$ denotes NVelectrospinning; * denotes $p<0.05$ ) 

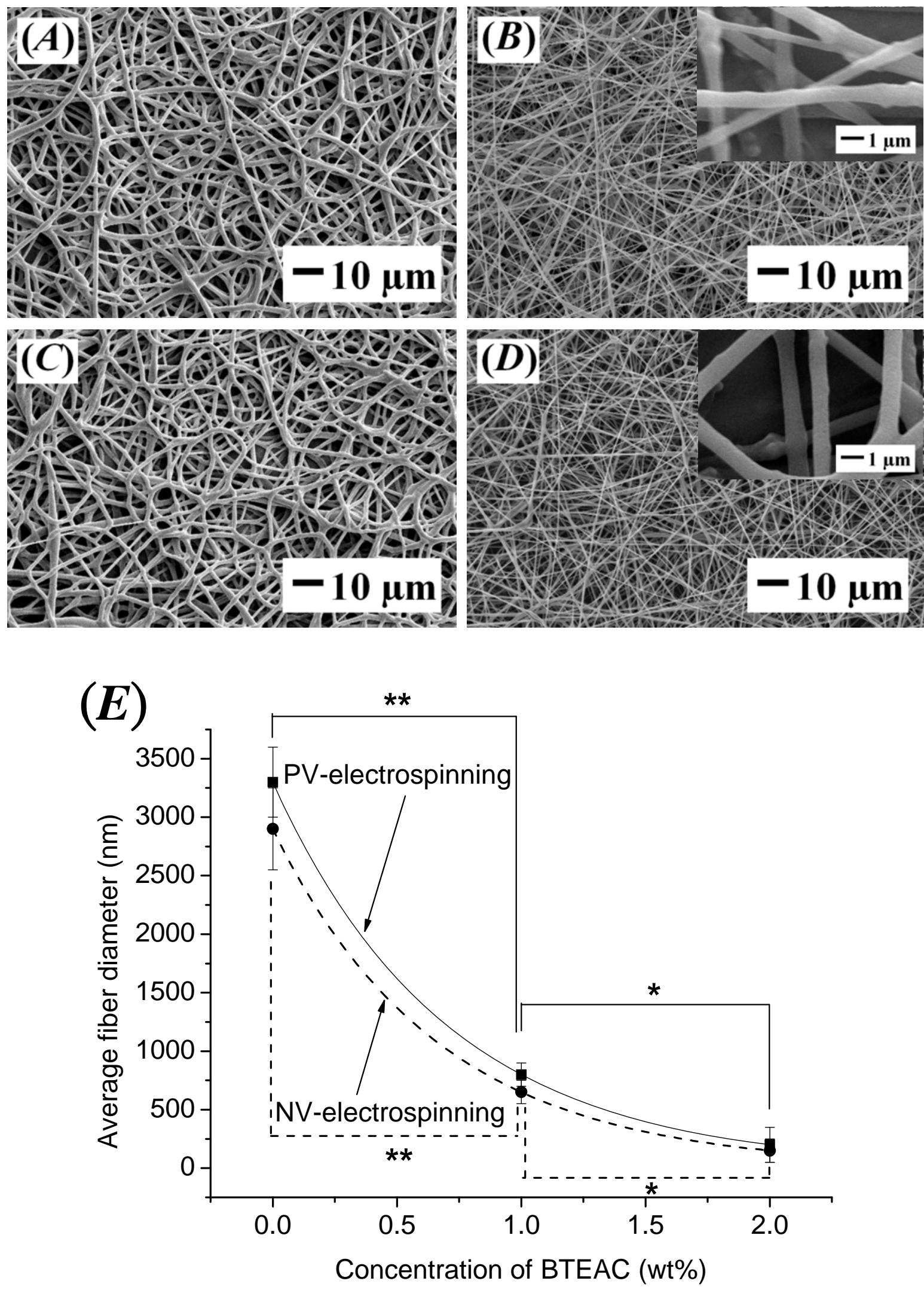

Figure 6. Electrospun PHBV fibers obtained using different BTEAC concentrations: $(A)$ at $0 \mathrm{wt} \%$ by $\mathrm{PV}$-electrospinning, $(B)$ at $2 \mathrm{wt} \%$ by $\mathrm{PV}$-electrospinning, $(C)$ at $0 \mathrm{wt} \%$ by $\mathrm{NV}$-electrospinning, $(D)$ at $2 \mathrm{wt} \%$ by NV-electrospinning, and $(E)$ relationship between BTEAC concentration and average fiber diameter for electrospun PHBV fibers. ( denotes PV-electrospinning; • denotes NVelectrospinning; $*$ denotes $p<0.05 ; * *$ denotes $p<0.01)$ 


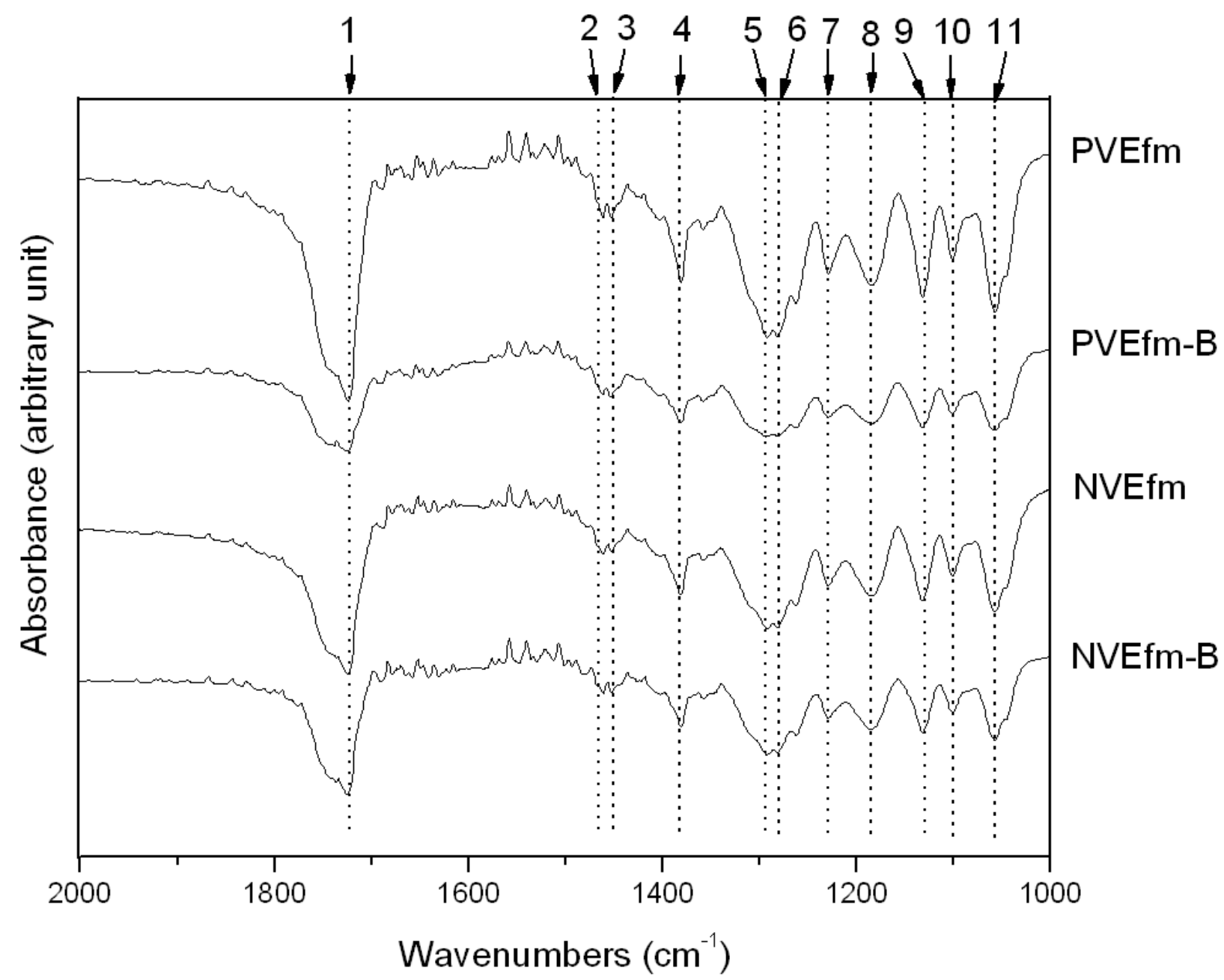

Figure 7. FTIR spectra of the four groups of fibrous PHBV membranes: PV-electrospun fibrous membrane from PHBV solutions without BTEAC (PVEfm), PV-electrospun fibrous membranes from PHBV solutions with BTEAC (PVEfm-B), NV-electrospun fibrous membrane from PHBV solutions without BTEAC (NVEfm), and NV-electrospun fibrous membranes from PHBV solutions with BTEAC (NVEfm-B) 
(A)
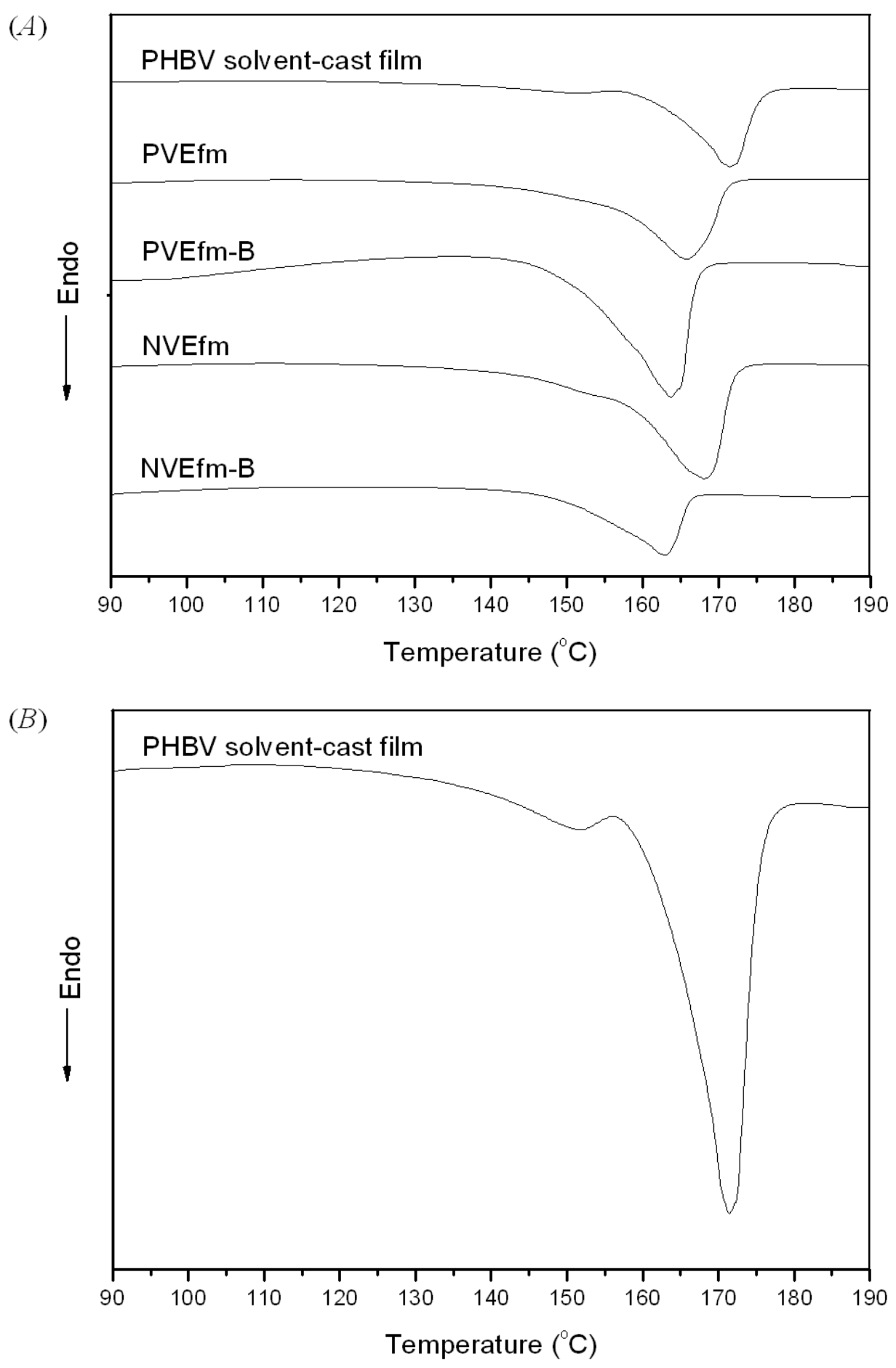

Figure 8. DSC thermograms: $(A)$ PHBV solvent-cast film and the four groups of electrospun fibrous membranes, $(B)$ the thermogram for PHBV solvent-cast film showing the shoulder peak 


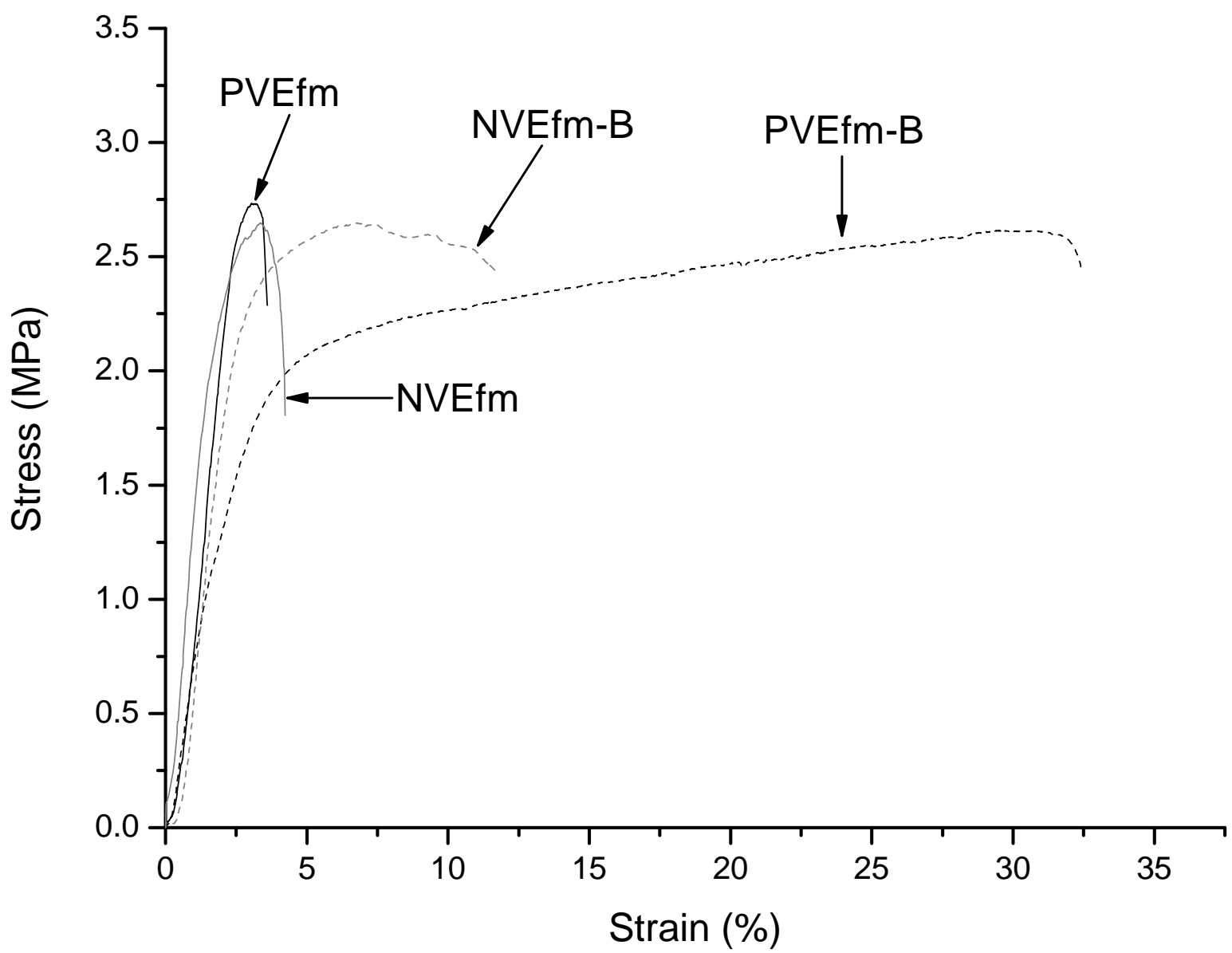

Figure 9. Stress-strain curves for the four groups of fibrous PHBV membranes: PV-electrospun fibrous membranes from PHBV solutions without BTEAC (PVEfm), PV-electrospun fibrous membranes from PHBV solutions with BTEAC (PVEfm-B), NV-electrospun fibrous membranes from PHBV solutions without BTEAC (NVEfm), and NV-electrospun fibrous membranes from PHBV solutions with BTEAC (NVEfm-B) 

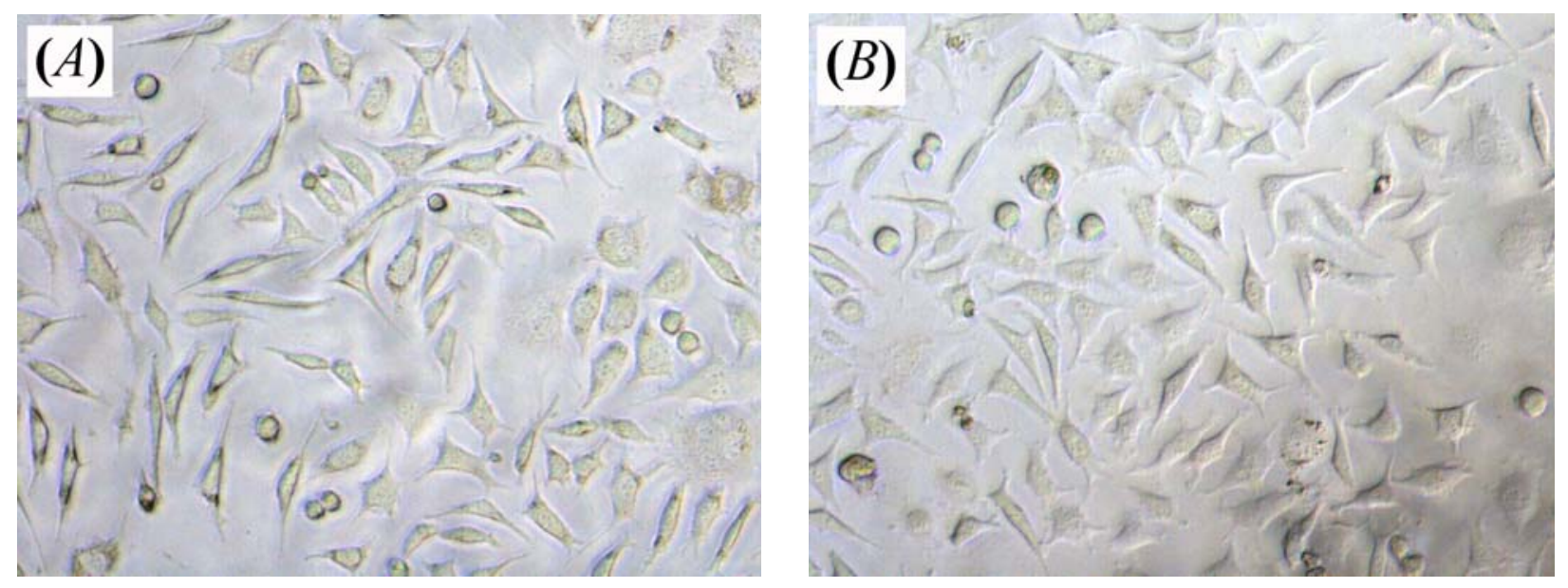

Figure 10. Morphology of L929 cells: $(A)$ after cell culture with an extraction medium containing PVelectrospun PHBV fibers, $(B)$ after cell culture with the culture medium of the control 

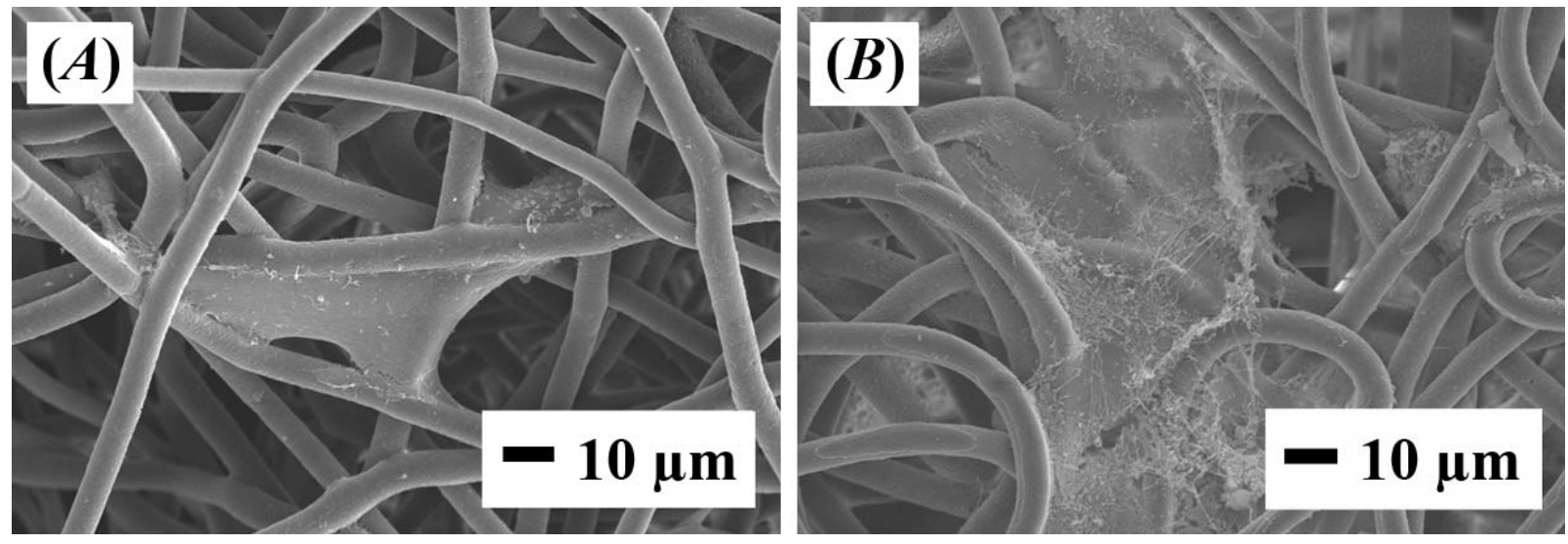

Figure 11. Morphology of SaOS-2 cells seeded on electrospun PHBV fibers after different cell culture times: $(A) 1$ week, $(B) 2$ weeks 